\title{
AN ANALYSIS OF FACTORS AFFECTING THE MEASUREMENT OF PULMONARY DIFFUSING CAPACITY BY THE SINGLE BREATH METHOD *
}

\author{
By JOHN B. CADIGAN, $\dagger$ ASHER MARKS, $\$$ MARJORIE F. ELLICOTT, ROBERT H. \\ JONES † AND EDWARD A. GAENSLER § \\ (From the Thorndike Memorial Laboratory and Second and Fourth (Harvard) Medical Serv- \\ ices, and the Thoracic Surgery Service, Boston City Hospital; the Departments of \\ Medicine and Surgery, Harvard Medical School; and the Thoracic Services, \\ Departments of Medicine and Surgery, Boston University School of \\ Medicine, Boston, Mass.)
}

(Submitted for publication April 8, 1960 ; accepted April 13, 1961)

The diffusing capacity of the lungs (DL) is defined as the rate of a gas transferred, divided by the difference in the mean partial pressure of that gas across the alveolar-capillary "membrane." Direct determination of the diffusing capacity for oxygen $\left(\mathrm{DL}_{\mathrm{O}_{2}}\right)$ has been limited by technical difficulties and by the problematical calculation of the mean oxygen pressure on the capillary side of the pulmonary membrane. Measurement of DL for carbon monoxide $\left(\mathrm{DL}_{\mathrm{CO}}\right)$ has been preferred because the affinity of $\mathrm{CO}$ for hemoglobin is so great that plasma tension or "back pressure" has been considered negligible and therefore disregarded (1).

The technique which Krogh (2) introduced for determination of $\mathrm{DL}_{\mathrm{CO}}$ involved measurement of alveolar $\mathrm{CO}$ pressure $\left(\overline{\mathrm{P}}_{\mathrm{A}} \mathrm{CO}\right)$ at the beginning and end of breath-holding. Gas containing $\mathrm{CO}$ was inhaled and a small portion exhaled immediately for determination of the initial $\mathrm{CO}$ pressure $\left(\overline{\mathrm{P}}_{\mathrm{A}_{\mathrm{CO}}}\right)$. A second sample was delivered at the end of the breath-holding period for measurement of the final $\mathrm{CO}$ pressure $\left(\overline{\mathrm{P}}_{\mathrm{A}_{\mathrm{COf}}}\right)$. Also determined were the volume of the lungs at which diffusion occurred (VA) and the barometric pressure (B). If $\overline{\mathrm{P}}_{\mathrm{A}_{\mathrm{CO}}}$ decays exponentially with time $(\mathrm{t})$ during breath-holding, and if the plasma back pressure is zero, then:

* This study was supported in part by a research grant from the National Heart Institute, United States Public Health Service (H-5933), Bethesda, Md.

$\dagger$ This study was performed during tenure of a U. S. Public Health Service Research Fellowship.

$\ddagger$ This study was performed during tenure of a Research Fellowship of the National Tuberculosis Association.

$\S$ This study was performed during tenure of an Edward Livingston Trudeau Fellowship.

$$
\mathrm{D}_{\mathrm{L}}^{1}=\frac{\mathrm{V}_{\mathrm{A}}}{\mathrm{B}-47} \times\left[\ln \frac{\left(\overline{\mathrm{P}}_{\mathrm{A}_{\mathrm{CO}_{\mathrm{i}}}}\right)}{\left(\overline{\mathrm{P}}_{\mathrm{A}_{\mathrm{CO}} \mathrm{f}}\right)}\right] \times
$$

The suggestion by Forster, Fowler, Bates and Van Lingen (3) to introduce nondiffusible helium as a tracer in the inspired gas has eliminated the need for initial "alveolar sampling." $\overline{\mathrm{P}}_{\mathrm{A}_{\mathrm{CO}} \text { of the }}$ previous equation can then be calculated from the helium concentration $\left(\mathrm{F}_{\mathrm{He}}\right)$ of the inspired and expired gases :

$$
\overline{\mathrm{P}}_{\mathrm{ACO}_{\mathrm{i}}}=\mathrm{PI}_{\mathrm{CO}} \times \frac{\mathrm{FE}_{\mathrm{He}}}{\mathrm{F}_{\mathrm{I}_{\mathrm{He}}}}
$$

This method is attractive for clinical estimation of the diffusing capacity because it is bloodless, and the entire test with analyses requires only a few minutes once the residual volume has been determined. However, during studies in our laboratories beginning in 1954 some disturbing facts emerged concerning this method. We noted that: a) values for the single breath $D_{L}$ in any given case were always larger than those obtained by either the $\mathrm{DL}_{\mathrm{CO}}$ or $\mathrm{DL}_{\mathrm{O}_{2}}$ steady state methods $(4) ; b)$ certain patients with reduced steady state $\mathrm{DL}_{\mathrm{O}_{2}}$ and $\mathrm{DL}_{\mathrm{CO}}$ had normal values by the single breath test $(4) ; c$ ) the $\mathrm{DL}_{\mathrm{co}}$ declined slightly with repeated determinations suggesting that mean pulmonary capillary CO pressure may not be negligible; and $d$ ) duplicate or multiple determinations often did not check satisfactorily. The largest deviations occurred when breaths were held at different lung volumes, and increases in lung volume of 50 per cent often caused a 50 per cent increase

\footnotetext{
1 Normally a subscript of $\mathrm{CO}$ or $\mathrm{O}_{2}$ is used to indicate the gas to which the measurement applies. In this article, which is mainly concerned with $\mathrm{CO}$, the subscript is omitted and can be assumed to be $\mathrm{CO}$ unless otherwise stated.
} 
of the single breath DL $(4,5)$. Such differences were first observed by Krogh (2) but recently Forster and associates $(3,6)$ and Ogilvie, Forster, Blakemore and Morton (7) have not been able to find significant differences in De due to changes in lung volume.

The purpose of the present study was, therefore: a) to study the relationship between alveolar volume (VA) and DL; b) to study the effects of plasma CO back pressure on the values obtained by the single breath technique; and $c$ ) to consider the reasons for the numerical differences between DL values obtained by the single breath and steady state techniques.

\section{METHODS}

The single breath DL was determined according to Krogh with the modifications of Forster and co-workers (3). Seated subjects inhaled a mixture containing approximately 0.3 per cent $C O, 20$ per cent $\mathrm{O}_{2}, 10$ per cent $\mathrm{He}$, and 70 per cent $\mathrm{N}_{2}$ through a large-bore, four-way valve from a box-balloon spirometer designed for this purpose. $^{2}$ The inspired volume was recorded by the spirometer attached to the box. Inspiration was made from residual volume at maximal speed. The period of breath-holding was timed with a stopwatch and could be checked in retrospect from the tracing obtained at a paper speed of $3.2 \mathrm{~cm}$ per second. Ordinarily, the stopwatch was started at the beginning of fast inspiration and stopped at the beginning of expiration. Timing errors were never more than 1 second except in patients with severe emphysema when timing was always a problem. After 10 seconds the gas was exhaled rapidly. Exhalation of about $1 \mathrm{~L}$ was allowed for valve and lung dead space washout prior to alveolar sample collection, except in patients with a vital capacity of less than $1.4 \mathrm{~L}$ in whom $600 \mathrm{ml}$ sufficed. A minimum of $350 \mathrm{ml}$ was required for $\mathrm{CO}_{2}, \mathrm{CO}$ and $\mathrm{He}$ analysis. The alveolar sample was then collected in a $2 \mathrm{~L}$ anesthesia bag with nipple.

Inspired and expired gases were analyzed for $\mathrm{CO}$ with an infrared meter. ${ }^{3}$ With the low amplification factor used for these experiments, samples could be analyzed with a reproducibility such that the standard deviation in any large number of $\mathrm{CO}$ analyses was less than 1 per cent of the mean value. The zero reading was adjusted with dry room air and the full-scale reading with inspired gas. Although the meter is known to respond slightly to $\mathrm{CO}_{2}$ due to overlapping absorption bands, gases containing up to 8 per cent $\mathrm{CO}_{2}$ produced no detectable deflection with the amplification used. The meter reading for expired gas was converted to percentage of

2 Box-balloon respirometer (no. P-1100) with fiveway Hans Rudolph Valve (no. P-326). Warren E. Collins, Inc., Boston, Mass.

${ }^{3}$ Gas analyzer, model 15, Iiston-Becker Co., Stamford, Conn. inspired gas by reference to our calibration curve. Details of measurement, calibration and over-all analytical error have been described elsewhere (8).

Helium concentrations were measured with a conventional catharometer. This instrument, however, responded significantly to $\mathrm{CO}_{2}$ concentrations of the magnitude encountered: 5 per cent $\mathrm{CO}_{2}$ caused an underestimation of the true helium concentration by about 0.8 per cent helium. Therefore, the gas sample always was first analyzed for $\mathrm{CO}_{2}$ with another infrared meter, ${ }^{4}$ or Scholander apparatus. Calibration curves constructed from known $\mathrm{He}-\mathrm{CO}_{2}$ mixtures, showing deflections due to varying amounts of $\mathrm{CO}_{2}$ at given meter readings, were used for correction. The same results were obtained when the $\mathrm{CO}_{2}$ was absorbed prior to helium analysis and a correction was made for volume change. Helium analyses were considered accurate within 0.2 vol per cent; an error of this magnitude may change the DL by 2 to 3 per cent. It is evident from Equations 1 and 2 that a constant analytical error of either $\mathrm{CO}$ or $\mathrm{He}$ cancels if it is of the same magnitude for both inspired and expired gases; and that the use of helium as a tracer eliminates errors due to apparatus dead space of either the inspiratory or expiratory circuits. All gas volumes were corrected to STPD.

For measurements of the DL at different lung volumes serial determinations were made. A long pointer, visible to the patient, was attached to the spirometer counterweight; the spirographic paper was marked at 1-L intervals and subjects were instructed to inspire to a different mark for each test. The actual volume inhaled on each occasion was measured from the spirogram with an accuracy of $\pm 10 \mathrm{ml}$. Exercise studies of both single breath and steady state DL were made with subjects walking on a treadmill at 3 miles per hour on an 8 per cent grade after a steady state had been achieved.

The residual volume, required for calculation of $V_{A}$, was measured by the open-circuit nitrogen washout method (9), modified by addition of an alveolar trap for determination of the "pulmonary mixing index" and a box-balloon system to ascertain the "switching error" (10).

Carboxyhemoglobin $(\mathrm{COHb})$ saturations, required for studies of back pressure, were determined according to the method of Gaensler and associates (8) in which all blood gases are extracted on the Van Slyke apparatus and analyzed with the infrared $\mathrm{CO}$ meter; this method is accurate to 0.02 vol per cent. The alveolar sampling method of Jones, Ellicott, Cadigan and Gaensler (11), in which the lungs are used as a tonometer, was used for rapid screening of $\mathrm{COHb}$ saturation and for determination of intermediate points during multiple studies.

The steady state $\mathrm{DL}_{\mathbf{C O}_{0}}$ was measured by the "physiological dead space" method of Filley, MacIntosh and Wright (12) with the subject in the supine position. DL may increase slightly with recumbency (13); the numerical differences here reported between the steady

\footnotetext{
${ }^{4}$ Gas analyzer, model 16, Iiston-Becker Co., Stamford,
} Conn. 
TABLE I

Variability of alveolar volume $\left(V_{A}\right)$ and the reproducibility of the single breath diffusing capacity $\left(D_{L_{c o}}\right)$

\begin{tabular}{|c|c|c|c|c|c|}
\hline \multirow[b]{2}{*}{ Group } & \multirow[b]{2}{*}{$\begin{array}{c}\text { No. } \\
\text { of } \\
\text { observations }\end{array}$} & \multicolumn{2}{|c|}{ Alveolar volume $\left(V_{A}\right)$} & \multicolumn{2}{|c|}{ Single breath $D_{L}$} \\
\hline & & Mean & $\begin{array}{l}\text { Coefficient } \\
\text { of } \\
\text { variation }\end{array}$ & Mean & $\begin{array}{c}\text { Coefficient } \\
\text { of } \\
\text { variation }\end{array}$ \\
\hline & & $m l$ & $\%$ & $\underset{m m ~}{m l / m i n /}$ & $\%$ \\
\hline 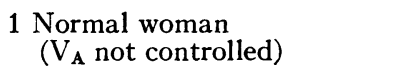 & 20 & 3,781 & \pm 11.9 & 20.2 & \pm 12.9 \\
\hline 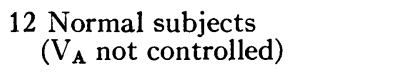 & 37 & 4,870 & \pm 7.2 & 30.6 & \pm 8.9 \\
\hline $\begin{array}{l}26 \text { Patients with alveolar- } \\
\text { capillary block syndrome } \\
(1955-1956) \\
\left(V_{A} \text { not controlled }\right)\end{array}$ & 52 & 3,770 & \pm 5.7 & 16.8 & \pm 10.7 \\
\hline $\begin{array}{l}21 \text { Patients with cardiac } \\
\text { disease } \\
\left(V_{A} \text { not controlled }\right)\end{array}$ & 42 & 3,481 & \pm 4.3 & 20.4 & \pm 7.4 \\
\hline $\begin{array}{l}1 \text { Normal man: } \\
\mathrm{V}_{\mathrm{A}} \text { held "constant" }\end{array}$ & 8 & 5,116 & \pm 1.4 & 28.1 & \pm 3.2 \\
\hline $\begin{array}{l}67 \text { Patients with alveolar- } \\
\text { capillary block syndrome } \\
(1957-1959)\end{array}$ & 221 & $\begin{array}{l}\text { Only } \\
100 \%\end{array}$ & $\begin{array}{l}\text { een 95- } \\
\text { effort used }\end{array}$ & 14.9 & \pm 2.6 \\
\hline
\end{tabular}

state and single breath methods, therefore, might have been even larger if the subjects had been in the same position during both determinations.

In the ensuing Discussion and illustrations, VA at which the breath was held is expressed as per cent of the total lung capacity (TLC), defined here as the sum of the residual volume and the largest vital capacity obtained either by single breath maneuver or conventional spirography. Studies at a VA lower than 40 per cent of TLC were difficult because about $1,350 \mathrm{ml}$ of gas was required for dead space washout and alveolar sample. Further, in older individuals the residual volume itself often occupied as much as 40 per cent of the TLC.

\section{RESULTS}

1. Variation of $D L$ with alveolar volume. With clinical use of the single breath technique, large differences were frequently observed between duplicate measurements. For example, in 1955 and 1956 paired observations of 26 patients with the "alveolar-capillary block" syndrome resulted in a coefficient of variation for the DL of 10.7 per cent ; individual measurements varied one from another by as much as 39 per cent. The error appeared to be the same or greater in normal subjects and was somewhat smaller in cardiac patients with restrictive ventilatory insufficiency (Table I). Whenever large variations between duplicates were obtained, it was observed that the greater value was almost always associated with the deeper inspiration or larger alveolar volume, VA. Since mere instruction to inhale maximally without practice or coaching resulted in variations of $\mathrm{VA}$ by as much as 40 per cent, an effort was made to keep VA constant. One normal subject, by observing the spirographic tracing, controlled inspiration so that for eight measurements of DL, VA remained within $70 \mathrm{ml}$ of the mean. The coefficient of variation of the DL for that series was reduced to 3 per cent (Table I). Because of this, during the next 3 years the lung volume has been considered in all clinical and statistical evaluations of single breath DL. As a result the coefficient of variation has been markedly reduced. For example, in 67 recent patients with alveolar-capillary block, the coefficient of variation was 2.6 per cent compared with 10.7 per cent in similar cases studied before 1957 (Table I). This variation is considerably lower than any previously reported $(7,14)$.

These observations suggested studies which would permit quantitation of the relationship between $\mathrm{VA}_{\mathrm{A}}$ and DL. A total of 248 determinations was made on 14 normal subjects and 15 patients with nonobstructive pulmonary disease (Tables II and III). The DL was measured in each individual at 4 to 15 different $V_{A}$ levels. The order of the latter was randomized to eliminate a systematic error due to accumulation of $\mathrm{CO}$ in the blood.

The results for normal subjects are summarized 


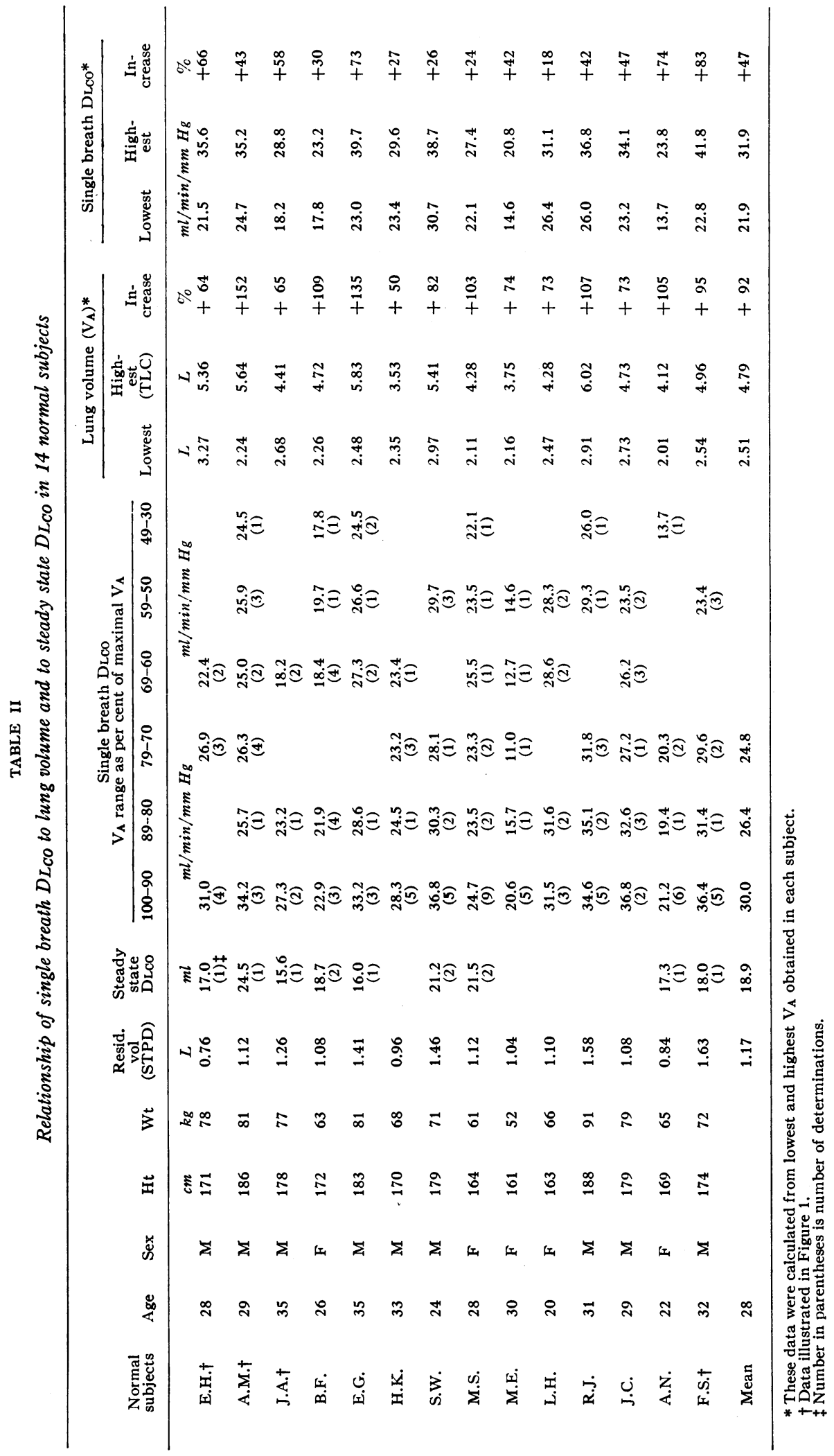


in Table II. Without exception there was a fall of Dr. as $V_{\Lambda}$ decreased. An average increase of VA of 91.9 per cent was accompanied by an average increase in DL of 46.6 per cent, and the latter increase was over 70 per cent in three subjects. Plotting of DL versus VA as percentage of TLC revealed three general types of curves, samples of which are shown in Figure 1. In some subjects the DL fell linearly with VA (E.W.H. and J.A.); in others there was an abrupt fall until VA reached 80 to 90 per cent of TLC after which a plateau was reached (A.M.). Decreases of this type were minimized in Table II because the data were grouped. A third curve, exemplified by Subject F.S., fell gently throughout the entire range.

Most of the patients shown in Table III had impaired diffusing capacities and classical alveolarcapillary block syndrome (4). For a given range of VA the mean DL values were lower than those of normal subjects, but for a smaller rise of $V_{\Lambda}$ there was an even larger rise of DL. This averaged 60 per cent for a 72 per cent rise of VA. Curves for four patients are shown in Figure 2.

During exercise the single breath DL increased as did the steady state DL, but even here a rise could be demonstrated with increasing lung volume (Table IV). In four subjects the mean increase of DL from minimal to maximal $V_{A}$ was 25 per cent both during rest and exercise.

A change of single breath diffusing capacity with changing lung volume might be anticipated from anatomic considerations. Because recent investigators have failed to demonstrate such variation $(3,6,7)$ we recalculated the original data of Krogh (2) for comparison with present results. In two of her cases there was sufficient variation in

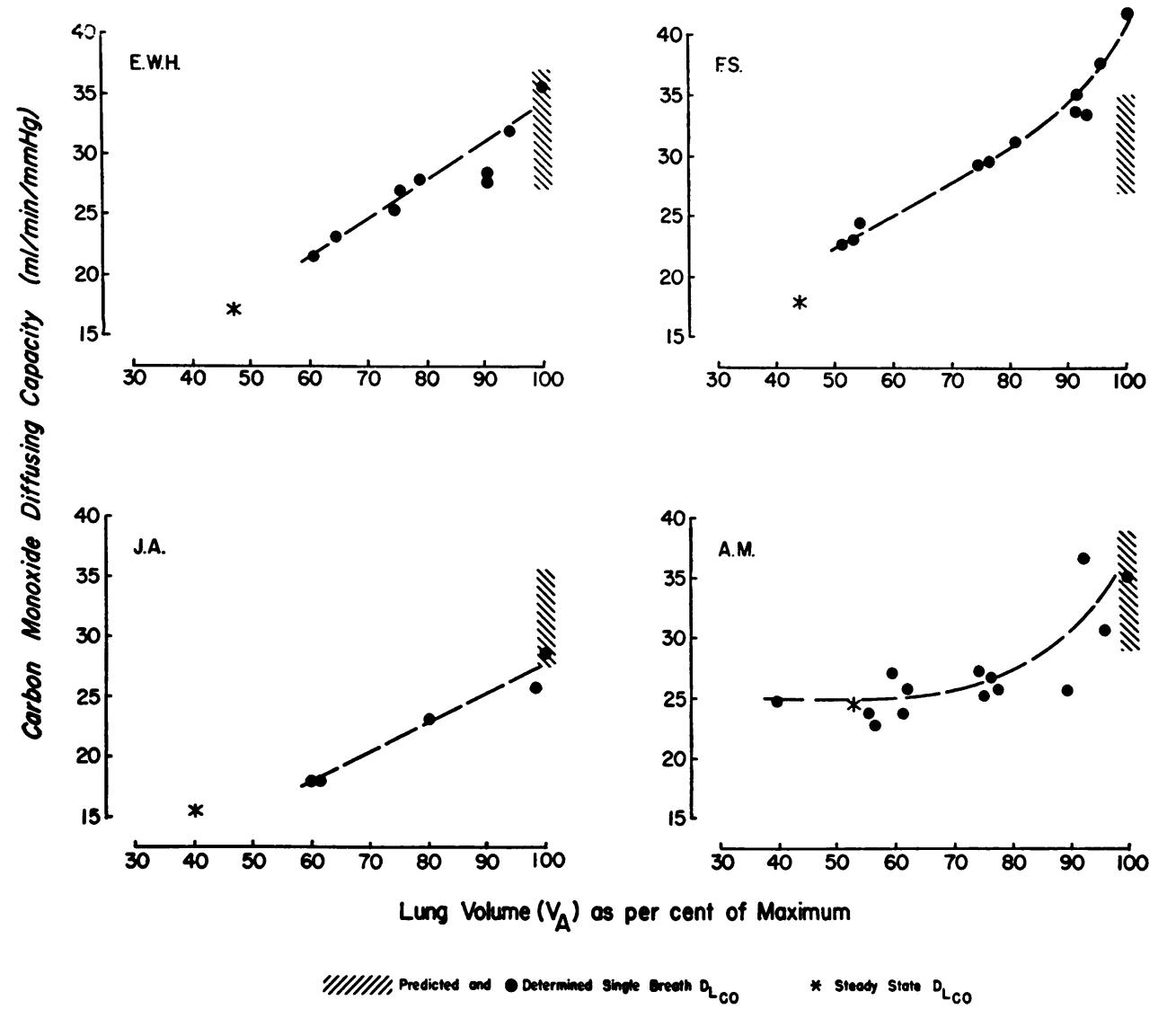

Fig. 1. The effect of the gas volume within the lungs (Va) at which the breath WAS HELD UPON THE SINGLE BREATH DIFFUSING CAPACITY (DL) IN FOUR NORMAL SUBJECTS (MEAN VALUES FOR GREATEST AND SMALLEST VA FOR 98 NORMAL SUBJECTS ARE SHOWN IN FIGURE 7). The stars indicate the physiological dead space steady state Dlco (12); for this the effective VA was assumed to be functional residual capacity plus one-half tidal volume. 


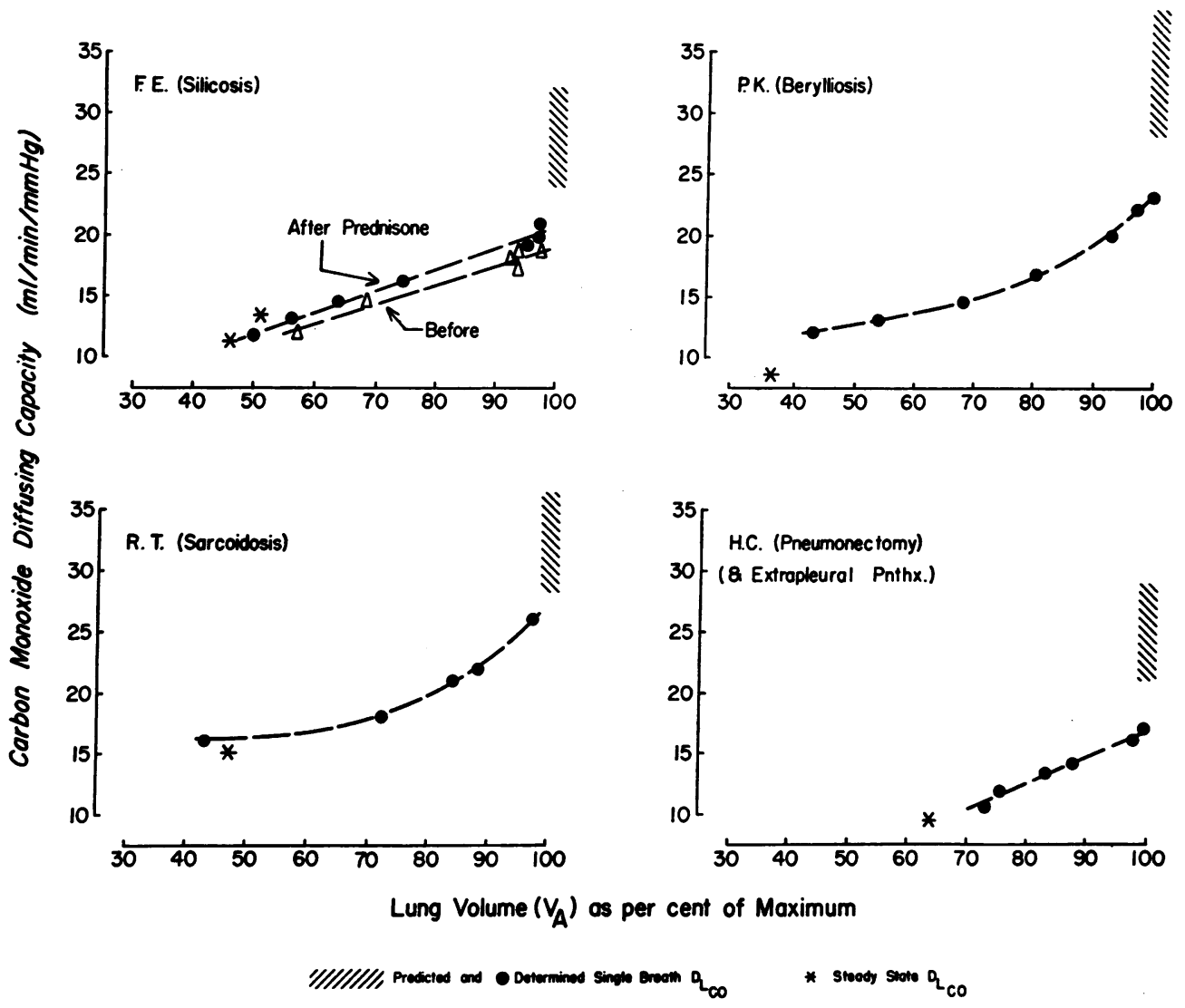

Fig. 2. The relationship of Single breath Dl to Va presented as in Figure 1, but for PATIENTS WiTh REDUCED DIfFusing CAPACITy. The first three had an alveolar-capillary block syndrome, while the last (H.C.) had a pneumonectomy on one side and an upper extrapleural pneumothorax of the remaining lung.

VA so that a plot could be made (Figure 3 ). The similarity of these curves to our plateau type shown in Figure 1 requires no comment.

2. "Instantaneous $D_{L}$." The demonstration that De changes with VA, together with the possibility that De may actually diminish during the period of breath-holding (3), suggests that the final value calculated by this method may be merely a composite due to several dynamic events occurring during the maneuver. An experiment was designed to measure the instantaneous value of $\mathrm{DL}$ while the $\mathrm{VA}_{\mathrm{A}}$ increased during inspiration, thus eliminating the decrease of DL which may occur while the breath is held.

Spirometer paper was marked with slopes representing given rates of inspiration. After some training the subject was able to inspire at a constant rate following these pre-drawn lines. Only two comparatively slow rates of inspiration, 300 and $525 \mathrm{ml}$ per second, were used because technical difficulties prevented inspiration at faster constant rates. Inhalation proceeded, starting from residual volume, at the predetermined rate and an alveolar sample was then delivered quickly without breath-holding. A number of points was obtained by ending inspirations at varying inspired volumes.

The rate at which $\mathrm{FA}_{\mathrm{CO}}$ should have risen during inspiration, were it not for diffusion, could be calculated from the ratio of expired to inspired helium (Figure 4, curve $A$ ). The actual $F_{A_{C O}}$ obtained by gas analysis is indicated by curve $B$. The concentration of $\mathrm{CO}$ within the lungs at any moment is the quantity of $\mathrm{CO}$ which has been inspired less the $\mathrm{CO}$ which has left by diffusion. The volume of $\mathrm{CO}$ which has been taken up by the blood at any given moment can be calculated by subtraction: curve $\mathrm{A}$ - curve $\mathrm{B}=$ curve $\mathrm{C}$. 
TABLE IV

The effect of lung volume and exercise* upon $D_{L_{c o}}$

\begin{tabular}{|c|c|c|c|c|c|c|c|c|c|c|c|c|c|c|}
\hline \multirow[b]{3}{*}{ Subject } & \multicolumn{9}{|c|}{ Single breath Deco $V_{A}$ range as per cent of maximal $V_{A}$} & \multicolumn{3}{|c|}{ Steady state DLco } & \multicolumn{2}{|c|}{$\begin{array}{l}\text { Per cent rise } \\
\text { of single } \\
\text { breath } D_{L} \\
\text { from lowest } \\
\text { to highest } \\
\text { value }\end{array}$} \\
\hline & \multicolumn{3}{|c|}{$100-90$} & \multicolumn{3}{|c|}{$89-70$} & \multicolumn{3}{|c|}{$69-50$} & \multirow[b]{2}{*}{ Rest } & \multirow[b]{2}{*}{$\begin{array}{l}\text { Exer- } \\
\text { cise }\end{array}$} & \multirow[b]{2}{*}{$\begin{array}{c}\% \\
\text { Rise }\end{array}$} & \multirow[b]{2}{*}{ Rest } & \multirow[b]{2}{*}{$\begin{array}{l}\text { Exer- } \\
\text { cise }\end{array}$} \\
\hline & Rest & $\begin{array}{l}\text { Exer- } \\
\text { cise }\end{array}$ & $\begin{array}{c}\% \\
\text { Rise }\end{array}$ & Rest & $\begin{array}{l}\text { Exer- } \\
\text { cise }\end{array}$ & $\begin{array}{c}\% \\
\text { Rise }\end{array}$ & Rest & $\begin{array}{l}\text { Exer- } \\
\text { cise }\end{array}$ & $\begin{array}{c}\% \\
\text { Rise }\end{array}$ & & & & & \\
\hline M.S. & $\begin{array}{c}24.7 \\
(9) \dagger\end{array}$ & $\begin{array}{c}34.2 \\
(3)\end{array}$ & +38 & $\begin{array}{l}23.4 \\
(4)\end{array}$ & $\begin{array}{l}29.2 \\
(1)\end{array}$ & +25 & $\underset{(2)}{24.5}$ & $\underset{\text { (1) }}{29.6}$ & +21 & ${ }_{(2)}^{21.5}$ & $\begin{array}{l}28.7 \\
\text { (1) }\end{array}$ & +33 & +1 & +16 \\
\hline s.w. & $\underset{(5)}{36.8}$ & $\begin{array}{l}42.5 \\
(2)\end{array}$ & +15 & $\begin{array}{c}29.5 \\
(3)\end{array}$ & & & $\begin{array}{c}29.7 \\
(3)\end{array}$ & $\begin{array}{c}31.5 \\
(2)\end{array}$ & +6 & $\begin{array}{c}21.2 \\
(2)\end{array}$ & $\begin{array}{c}36.5 \\
(1)\end{array}$ & +72 & +24 & +35 \\
\hline A.M. & $\frac{34.2}{(3)}$ & $\begin{array}{c}45.9 \\
(2)\end{array}$ & +34 & $\begin{array}{c}26.1 \\
(5)\end{array}$ & $\begin{array}{c}39.5 \\
(1)\end{array}$ & +51 & $\begin{array}{c}25.4 \\
(5)\end{array}$ & & & $\underset{(1)}{24.5}$ & $\begin{array}{c}35.2 \\
(1)\end{array}$ & +44 & +35 & +16 \\
\hline E.H. & $\begin{array}{c}31.0 \\
(4)\end{array}$ & & & $\begin{array}{c}26.9 \\
(3)\end{array}$ & $\begin{array}{l}46.0 \\
(1)\end{array}$ & +71 & $\begin{array}{l}22.4 \\
(2)\end{array}$ & $\begin{array}{l}35.0 \\
(\mathbf{1})\end{array}$ & +56 & $\underset{(1)}{17.0}$ & $\begin{array}{c}35.0 \\
(1)\end{array}$ & +106 & +38 & +31 \\
\hline Mean & 31.9 & 40.9 & +29 & 25.5 & 38.2 & +49 & 25.5 & 32.0 & +28 & 21.1 & 33.9 & +64 & +25 & +25 \\
\hline
\end{tabular}

* Steady exercise on treadmill on 8 per cent grade walking 3 miles per hour.

$\ddagger$ Number in parentheses is number of observations.
$\ddagger$ Means include only those values where both rest and exercise data were obtained.

The rate of $\mathrm{CO}$ loss due to diffusion at time $t$ is the slope of curve $\mathrm{C}, \mathrm{dV}_{\mathrm{Co}} / \mathrm{dt}$. The "instantaneous" DL (shown by curve D) can then be calculated for any given moment by dividing the slope of curve $\mathrm{C}\left(\mathrm{dV}_{\mathrm{co}} / \mathrm{dt}\right)$ by the partial pressure of

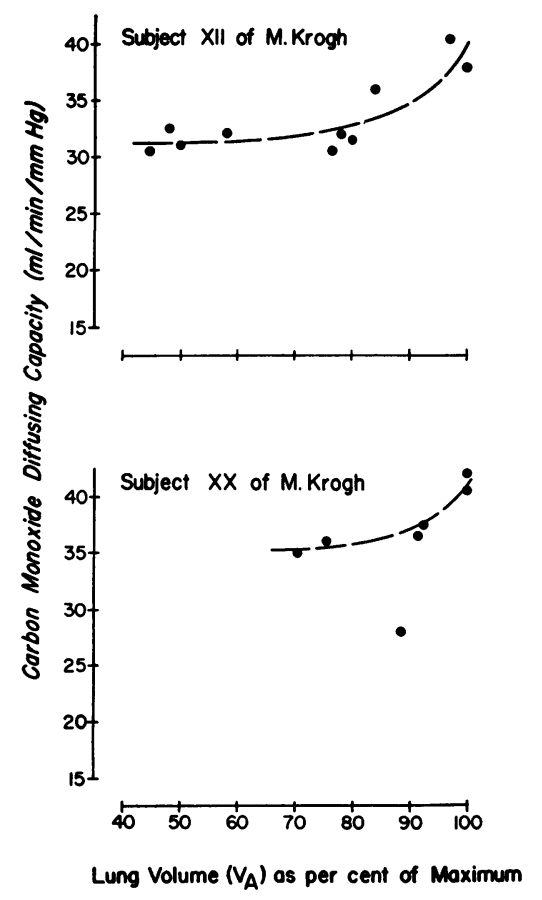

Fig. 3. The relationship of Single breath Dl and VA IN TWO NORMAL SUBJECTS RECALCULATED FROM DATA OF KROGH (2).
$\mathrm{CO}$ in the alveoli (curve $\mathrm{B} \times[\mathrm{B}-47]$ ) at that moment. The slope of curve $\mathrm{C}$ can be obtained graphically. The final curve, D, shows the instantaneous DL obtained in this manner at the two rates of inspiration. At the slower rate the De changed with VA just as with the plateau-type curves previously shown (Figure 1); at the faster rate the Du starts to rise almost at once and continues to rise throughout inspiration. The shape of curve $\mathrm{D}$ would be altered materially by correction for back pressure, to be discussed subsequently. Obviously, the relationships shown in Figure 4 may be expressed algebraically in the form of differential equations. ${ }^{5}$ Unfortunately, the final equation for curve $\mathrm{D}$ contains the expression for the slope of curve $\mathrm{B}$ or $\mathrm{C}$ which must still be obtained by graphic construction.

3. The effect of CO back pressure upon $D L$. The calculation of DL by Equation 1 depends upon the validity of the assumption that the carbon monoxide in the pulmonary capillary blood exerts no significant pressure (back pressure). It is now known that there is not sufficient time in the pulmonary capillary for complete equilibration to occur between $\mathrm{CO}$ in free solution and that combined with hemoglobin $(15,16)$. The plasma CO tension in the capillary, which is neglected in Equation 1 , is a complex function of the hemoglobincarbon monoxide reaction time, mixed venous

\footnotetext{
${ }^{5}$ See Appendix.
} 
carboxyhemoglobin saturation, rate of $\mathrm{CO}$ uptake, and the velocity of blood in the capillaries $(1,2$, 15-17). Consequently, under the unique conditions of this test it may not be valid simply to use Haldane's " $M$ " for the estimation of back pressure. To circumvent the problems of measuring the actual plasma tension, experiments were made to show: $a$ ) the change of $\mathrm{COHb}$ saturation with multiple single breath determinations, $b$ ) the effect of this change in saturation upon the $\mathrm{DL}$ actually obtained, and $c$ ) the order of magnitude of the back pressure which probably exists.

In five normal subjects the $\mathrm{COHb}$ saturation was raised by several periods of 0.1 per cent $C O$ breathing. Multiple determinations of $\mathrm{DL}$ (at maximal $\mathrm{VA}$ ) and of $\mathrm{COHb}$ saturations were made before and after each $\mathrm{CO}$ breathing period. At least 5 minutes was allowed between each test and each $\mathrm{CO}$ breathing to permit re-equilibration of the lungs with ambient air. The $\mathrm{CO}$ uptake resulting from both the $\mathrm{CO}$ breathing and the breath-holding tests was calculated and recorded. The measured $\mathrm{COHb}$ saturation was compared to a $\mathrm{COHb}$ saturation calculated from this $\mathrm{CO}$ uptake and an assumed blood volume. The two values were nearly the same at saturations up to 15 per cent. At higher saturations the measured blood saturation was always lower than that calculated from CO uptake, presumably because of the greater rate of $\mathrm{CO}$ loss from the lungs during intervals between tests.

The single breath $\mathrm{DL}_{\mathrm{L}}$ obtained at constant $\mathrm{VA}_{\mathrm{A}}$ was plotted for different $\mathrm{COHb}$ saturations (Figure 5). The slopes indicate the decrease in apparent $\mathrm{DL}$ with increasing $\mathrm{COHb}$ saturation. This decrease ranged from 0.15 to $0.32 \mathrm{ml}$ per minute per $\mathrm{mm} \mathrm{Hg}$ per 1 per cent $\mathrm{COHb}$, with a mean value of 0.27 . Extrapolation of the slopes to the ordinate was somewhat uncertain in the two smokers, E. G. and J. C., and not difficult in the three nonsmokers. If one assumes that the back pressure is zero at the ordinate where $\mathrm{COHb}$ saturation is zero, then the intercept would be the "true DL." Further, it should be possible to correct $\mathrm{DL}$ values observed at other than zero $\mathrm{COHb}$ saturation for the effect of back pressure. Such a correction was made for all values in each subject (Figure 5) using Haldane's equation, assuming $\mathrm{M}=245$, mean pulmonary capillary $\mathrm{Po}_{2}$ $=85 \mathrm{~mm} \mathrm{Hg}$, and $\mathrm{COHb}+\mathrm{O}_{2} \mathrm{Hb}=95$ per cent
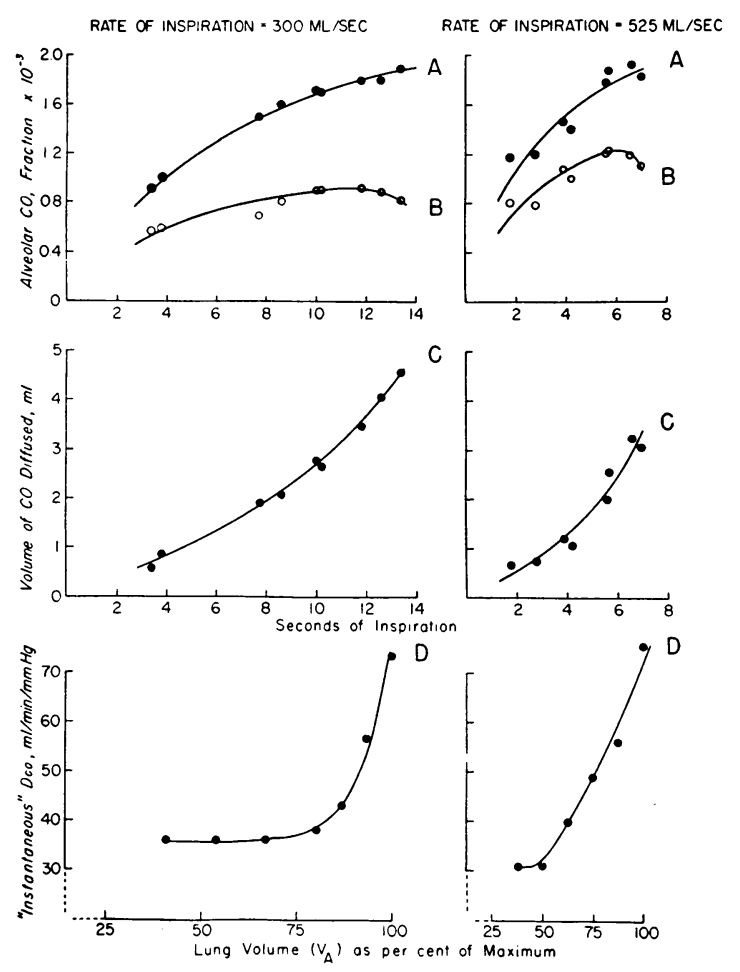

Fig. 4. The instantaneous Dl obtained without BREATH-HOLDING DURING TWO DIFFERENT STEADY RATES OF INSPIRATION. The rate of increase of alveolar $\mathrm{CO}$ tension which would have existed if no diffusion had occurred (curve A) was calculated from helium ratios. The actual alveolar $\mathrm{CO}$ tension, obtained from alveolar samples, is indicated by curve B. The volume of CO which had diffused out of the lungs at any given moment (curve C) was obtained by subtracting curve $B$ from curve A. The rate at which $\mathrm{CO}$ left the lungs, indicated by the slope of curve $\mathrm{C}$, was obtained graphically. This slope, at any point, divided by the alveolar CO tension at that time is, by definition, the diffusing capacity. This instantaneous DL plotted against the lung volume (VA) at that instant is indicated by curve D. (Note the change in abscissa.)

(11). The corrected values should lie on a horizontal line at the level of the true DL. However, this was never the case since the back pressure correction, so calculated, was invariably too low. In fact, no adequate correction could be obtained with Haldane's equation using several other reasonable values for $\mathrm{M}, \overline{\mathrm{P}} \mathrm{a}_{2}$, and saturation.

An "effective back pressure," $P_{\mathrm{e}}$, was calculated for each observed Du value such that the corrected De became equal to true DL, again assuming that back pressure is zero at zero $\mathrm{COHb}$ saturation. These $\mathrm{P}_{\mathrm{e}}$ values, plotted against corresponding 
$\mathrm{COHb}$ saturations at the bottom of Figure 5, resulted in carboxyhemoglobin dissociation curves effective during these special conditions for each individual subject. $\mathrm{P}_{\mathrm{e}}$ was from 1.3 to 2.5 times greater than back pressures calculated from $\mathrm{Hal}$ dane's equation.

Forster and co-workers (3) found that, contrary to theory, the relation between the logarithm of alveolar $\mathrm{CO}$ tension and the time of breath-holding was not linear even when correction was made for back pressure. Three such breath-holding curves are plotted for E. G. at 5.5, 11.8 and 17.0 per cent $\mathrm{COHb}$ saturation in Figure 6. If the $\mathrm{P}_{\mathrm{e}}$ values from Figure 5 are subtracted, three straight lines are inscribed. The empirically calculated $\mathrm{P}_{\mathrm{e}}$ correction from Figure 5 must pro-

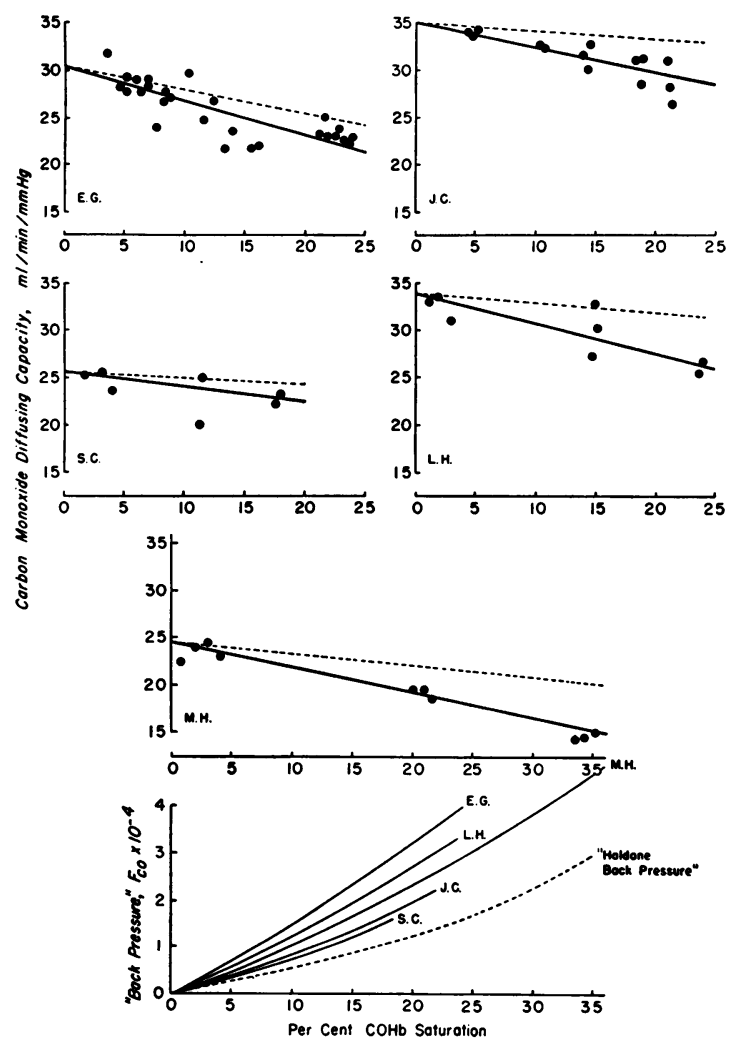

Fig. 5. Alteration of the apparent Dl with inCreasing COHb saturation. The first two subjects (E. G. and J. C.) were smokers; the other three were not. The broken lines indicate the "correction" of DL resulting from use of Haldane's equation. The lowest graph shows the effective back pressure at various $\mathrm{COHb}$ saturations assuming: $a$ ) a zero plasma $\mathrm{CO}$ tension at zero saturation, and $b$ ) that the progressive decline of DL was solely a function of back pressure. duce the same slope for 10 -second breath-holding at all $\mathrm{COHb}$ saturations, since this was the assumption for calculation of $\mathrm{P}_{\mathrm{e}}$. The fact that the corrected slopes are the same also at 20 seconds, despite differences in $\mathrm{COHb}$ saturation, and that straight lines are produced up to 60 seconds in the two other subjects (Figure 6) suggests that the observed alinearity is not the result of different diffusing phases, as stipulated by Forster and associates (3) but rather due to back pressure. Decay curves at two different lung volumes in Subject A. M. (Figure 6) were also straightened but the slopes remained dissimilar. This suggests that the change in DL with VA is not due to back pressure effect alone. These results appear to support the original assumption that back pressure is zero at zero $\mathrm{COHb}$ saturation, that the concept of true $\mathrm{DL}_{\mathrm{L}}$ is valid, and that $\mathrm{P}_{\mathrm{e}}$, in fact, is the effective back pressure.

4. The relationship between the steady state and single breath methods. The steady state $\mathrm{DL}_{\mathrm{CO}}$ and $\mathrm{DL}_{\mathrm{O}_{2}}$ values are usually quite comparable, but the single breath $\mathrm{DL}_{\mathrm{CO}}$ is always much larger. For example, in nine normal subjects the mean steady state value at rest was $18.9 \mathrm{ml}$ per minute per $\mathrm{mm} \mathrm{Hg}$ compared with $32.7 \mathrm{ml}$ by the single breath technique (Table II), and in patients without obstructive disease the latter value was 2.4 times larger than the former (4). However, if the two determinations are made at comparable lung volumes (considering VA for the steady state maneuver to be equal to FRC plus one-half the tidal volume), the difference vanishes. In five of our normal subjects (Table II) we obtained the De by both techniques at comparable VA, that is, 30 to 49 per cent of TLC. For these five, the steady state DL averaged 19.6 and the single breath DL at comparable VA averaged $20.5 \mathrm{ml}$ per minute per $\mathrm{mm} \mathrm{Hg}$. The mean single breath $\mathrm{DL}$ for the same five subjects at maximal inspiration (90 to 100 per cent of TLC) was 27.2. The same was true for the eight patients of Table III in whom values were obtained at comparable lung volumes; here the mean single breath $\mathrm{DL}_{\mathrm{L}}$ (at 30 to 59 per cent of $\mathrm{VA}_{\text {A }}$ ) was 12.8 and the mean steady state De $11.8 \mathrm{ml}$ per minute per $\mathrm{mm} \mathrm{Hg}$. This relationship is also indicated in Figures 1 and 2.

It seemed, therefore, that the different results obtained by the two techniques were a function of 


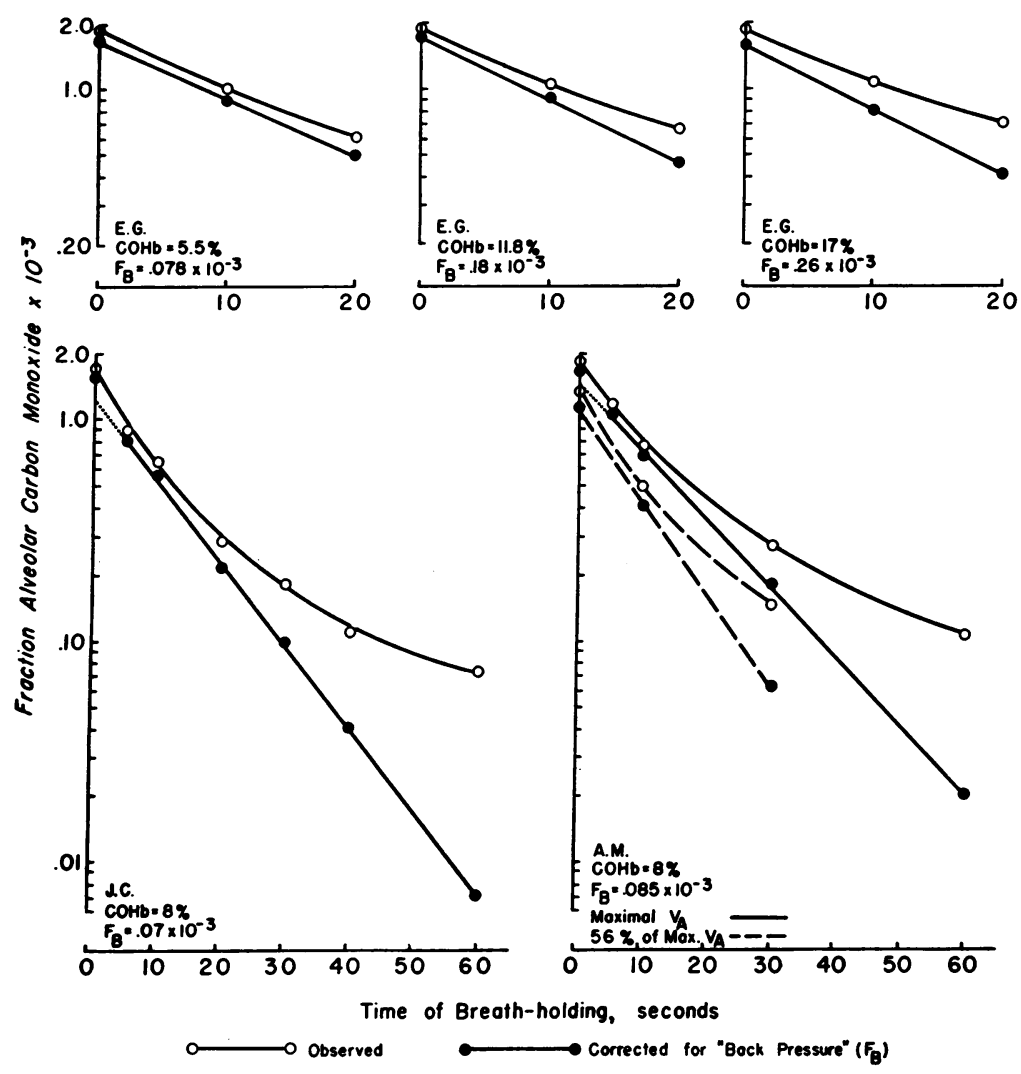

Fig. 6. The Relationship of the NatURAL LOGARithM OF alveolar CO CONCENTRATION TO THE TIME OF BREATH-HOLDING WITHOUT CORRECTION FOR BACK PRESSURE AND WITH CORRECTIONS OBTAINED FROM DATA OF FiguRE 5. All values were obtained at maximal $V_{A}$ except the second set of Subject A. M. for which the breath was held at 56 per cent of VA.

the lung volume at which the measurements were made. Attempting to prove this, experiments were performed in which lung volume was changed during steady state $\mathrm{CO}$ breathing. Three subjects were placed in a body plethysmograph with head and one arm protruding for arterial sampling. $\mathrm{VA}$ was changed by altering the pressure within the chamber stepwise from +10 to $-20 \mathrm{~cm}$ of water. A $20 \mathrm{~cm}$ decrease in pressure resulted in an increase in FRC of 1,200 to $3,000 \mathrm{ml}$. At least 30 minutes was allowed between each determination for return to a steady state at the new FRC. All measurements on a single subject were made within a 5 hour period. The data are arranged in Table $\mathrm{V}$ according to increasing VA. Under these experimental conditions, no increase of DL could be demonstrated with an increase in lung volume. On the contrary, there seemed to be a slight decrease which was presumed to have resulted from a progressive rise of $\mathrm{COHb}$ saturation and hence a rise in back pressure. This is emphasized if tests are rearranged in order of performance instead of lung volume. To correct for this factor, the plasma tension was estimated from Haldane's equations and known $\mathrm{CO}$ uptake. This correction failed to reveal a rise of DL with VA, and examination of Table $\mathrm{V}$ suggests that no manner of back pressure correction could alter the data to show a concomitant rise of DL with VA. The results are further complicated by the fact that lowering of plethysmograph pressure has the same physiological consequences as continuous positive pressure breathing and its effect on thoracic, and possibly on pulmonary capillary, blood volume. Since these studies were made, Grape and Tyler (18), using end tidal sampling measurements, were able to demonstrate some increase of steady state $\mathrm{DL}_{\mathrm{L}}$ with increasing FRC, but since then we have not 
TABLE V

The steady state DLco with lung volume variations induced by altering ambient pressure

\begin{tabular}{|c|c|c|c|c|c|c|c|c|c|c|}
\hline Subject & $\begin{array}{l}\text { Order } \\
\text { of } \\
\text { expts. }\end{array}$ & $\begin{array}{c}\text { Body } \\
\text { tank } \\
\text { pressure }\end{array}$ & $\begin{array}{l}\text { Minutes of } \\
0.1 \% \text { CO } \\
\text { breathing }\end{array}$ & $\begin{array}{c}\mathrm{CO} \\
\text { uptake }\end{array}$ & $\overline{\mathbf{P a c o}}$ & $\begin{array}{c}\text { Estimated* } \\
\% \text { coHb } \\
\text { during } \\
\text { 3-min } \\
\text { test }\end{array}$ & $\begin{array}{l}\text { Estimated } \\
\text { CO back } \\
\text { pressure }\end{array}$ & DL.CO & $\begin{array}{l}\text { DLco } \\
\text { corrected } \\
\text { for back } \\
\text { pressure }\end{array}$ & $\begin{array}{l}\text { Lung } \\
\text { volume }\left(V_{A}\right)\end{array}$ \\
\hline E.G. & $\begin{array}{l}1 \\
3 \\
2 \\
4\end{array}$ & $\begin{array}{c}\mathrm{Cm} \mathrm{H}_{2} \mathrm{O} \\
0 \\
-10 \\
-15 \\
-20\end{array}$ & $\begin{array}{r}10 \\
10 \\
12 \\
9\end{array}$ & $\begin{array}{c}m l / m i n \\
2.35 \\
2.22 \\
2.12 \\
2.17\end{array}$ & $\begin{array}{r}m m H g \\
0.144 \\
0.166 \\
0.146 \\
0.186\end{array}$ & $\begin{array}{l}6.45 \\
8.85 \\
7.85 \\
9.95\end{array}$ & $\begin{array}{c}m m \mathrm{Hg} \\
0.028 \\
0.040 \\
0.035 \\
0.046\end{array}$ & $\begin{array}{c}\mathrm{ml} / \mathrm{min} / \mathrm{mm} \\
16.3 \\
13.4 \\
14.5 \\
11.7\end{array}$ & $\begin{array}{l}20.2 \\
17.6 \\
19.1 \\
15.5\end{array}$ & $\begin{array}{c}m l \\
1,698 \\
2,704 \\
3,340 \\
4,183\end{array}$ \\
\hline W.A. & $\begin{array}{l}3 \\
1 \\
2 \\
4\end{array}$ & $\begin{array}{r}+10 \\
0 \\
-10 \\
-20\end{array}$ & $\begin{array}{l}9 \\
9 \\
9 \\
9\end{array}$ & $\begin{array}{l}1.82 \\
2.26 \\
2.00 \\
2.12\end{array}$ & $\begin{array}{l}0.154 \\
0.146 \\
0.142 \\
0.150\end{array}$ & $\begin{array}{l}8.18 \\
6.27 \\
7.27 \\
8.98\end{array}$ & $\begin{array}{l}0.035 \\
0.028 \\
0.032 \\
0.041\end{array}$ & $\begin{array}{l}12.6 \\
15.5 \\
14.1 \\
14.1\end{array}$ & $\begin{array}{l}15.3 \\
19.2 \\
18.2 \\
19.4\end{array}$ & $\begin{array}{l}1,631 \\
2,186 \\
3,210 \\
4,567\end{array}$ \\
\hline H.M. & $\begin{array}{l}3 \\
2 \\
1\end{array}$ & $\begin{array}{r}0 \\
-10 \\
-20\end{array}$ & $\begin{array}{l}9 \\
9 \\
9\end{array}$ & $\begin{array}{l}5.33 \\
5.49 \\
5.75\end{array}$ & $\begin{array}{l}0.258 \\
0.256 \\
0.268\end{array}$ & $\begin{array}{l}8.18 \\
7.27 \\
6.27\end{array}$ & $\begin{array}{l}0.035 \\
0.032 \\
0.028\end{array}$ & $\begin{array}{l}20.7 \\
21.4 \\
21.5\end{array}$ & $\begin{array}{l}23.9 \\
24.5 \\
24.0\end{array}$ & $\begin{array}{l}2,093 \\
2,573 \\
3,204\end{array}$ \\
\hline
\end{tabular}

* Initial $\mathrm{COHb}$ saturation was estimated from smoking history; for each minute of $0.1 \% \mathrm{CO}$ breathing a $0.17 \%$ rise in $\mathrm{COHb}$ saturation was assumed; the derived value is the mean for the last 3 minutes of the first test. Subsequent tests were made at 30-minute intervals; for these a half-life $\mathrm{COHb}$ of 4.5 hours_was_assumed.

been able to reproduce their results either by the physiological dead space technique or by end tidal sampling.

\section{DISCUSSION}

Analysis of previous data from our laboratory was made, and a series of experiments was undertaken, in an attempt to explain the considerable variability of the single breath $\mathrm{DL}_{\mathrm{Co}}$, and its large numerical difference from the steady state values.

Variations in the lung volume at which the breath was held appeared to explain in large part the variability of the test (Table I). Careful control of the lung volume has increased the clinical usefulness of the procedure (5). A rising back pressure was ruled out as a source of serious variation in repetitive tests (Figure 5). The cumulative effect of plasma $\mathrm{CO}$ was so small that the progressive change in DL was within the limit of error of the various physical analytical procedures unless more than 10 or 12 consecutive observations were made.

As soon as the test was devised by Krogh (2) she noted changes in the diffusing capacity related to alveolar volume. Because DL decreased in proportion to $\mathrm{VA}$ until FRC was reached but remained unchanged thereafter, she postulated that the effective membrane progressively decreased in size down to FRC, but that further reduction of DL from this point on was prevented by infolding of the membrane. Forster, Ogilvie and their as- sociates $(3,6,7,19)$ were not able to confirm this finding and thought that Krogh's results were due to the variable conditions of the initial alveolar sampling which they had eliminated by the use of helium. Recently, they reported data of five patients with a mean increase of DL of only 9 per cent as VA rose 53 per cent from 3 to $4.6 \mathrm{~L}$ (7). However, the low VA was considerably above FRC, and the inclusion of one subject with an unusually high DL at the low volume weighted the results. Excluding this individual, the mean increase of VA would have been 15 per cent.

Data obtained with the helium technique supporting Krogh's contention were first mentioned in a study from our laboratory comparing different methods (4), and have since been confirmed by others $(14,20,21)$. More recently, in an effort to develop a prediction formula for the single breath $\mathrm{DL}$, we found a significant variation of $\mathrm{DL}$ with VA in all but 4 of 98 normal subjects (Figure 7) ; and in 22 patients with chronic beryllium poisoning who had a series of single breath tests at widely differing lung volumes, the expected correlation with VA was found every time (5).

The second problem, the numerical difference between the apparent DL determined by the single breath and the steady state techniques, appeared to be closely related. Unlike the controversy concerning the single breath DL-VA relationship, there is little argument that, at rest, the single 
breath test results in much larger values than the steady state DL, however determined $(4,14$, 20, 22). A single dissenting opinion (13) appears to have been based on a laboratory analytical error (23).

The total resistance to diffusion, $1 / \mathrm{DL}$, has been shown to be a composite of the resistance across the pulmonary membrane separating alveolar air from the surface of the red cell, 1/DM, and the "intracapillary resistance" due to the time taken for $\mathrm{CO}$ diffusion into the red blood cells and reaction with hemoglobin, $1 / \theta \mathrm{V}_{\mathfrak{c}} ; \theta$ is the number of milliliters of CO taken up by the red cells in $1 \mathrm{ml}$ of blood per minute per $1 \mathrm{~mm} \mathrm{Hg}$ pressure gradient of dissolved gas between the plasma and the interior of the red cell, and $V_{c}$ is the total volume in milliliters of blood in the lung capillaries exposed to alveolar air $(17,24)$.

Consideration of the factors affecting the magnitude of DL obtained by different techniques and at different lung volumes thus must include: $a$ ) possible variations of $\mathrm{DM}_{\mathrm{M}}$ and $\mathrm{V}_{\mathfrak{c}}, b$ ) whether $\mathrm{CO}$ back pressure is equally "negligible" under all circumstances, and $c$ ) whether in a given individual "the same lung" is being sampled under different circumstances.

The reaction rate, $\theta$, can be excluded from consideration. In the same individual at rest, $\theta$ can be changed only by altering significantly the mean pulmonary capillary oxygen tension. This is not the case in the techniques under consideration.

The diffusing capacity of the membrane, DM, using the same gas, can be altered only by changing the thickness or area or both of the gas-blood interphase. Krogh (2) and several investigators since $(14,20,25,26)$ have attributed the increase of DL with increasing VA to a stretching and consequent thinning and increase in area of the membrane. Even the increase of DL with exercise has been attributed to a larger membrane surface resulting from an elevation of the pulmonary midposition $(25,26)$. Few data appear to support this thesis. The fact that the steady state $D_{L}$ value falls on a line relating single breath $D_{L}$ and $V_{A}$ at a point where $V_{A}$ approximately equals FRC (Figures 1 and 2) may be fortuitous because the usual calculations underestimate the true steady state DL (27). Our determinations of this value during body-respirator-induced increase of FRC also do not lend support to the "stretch theory."

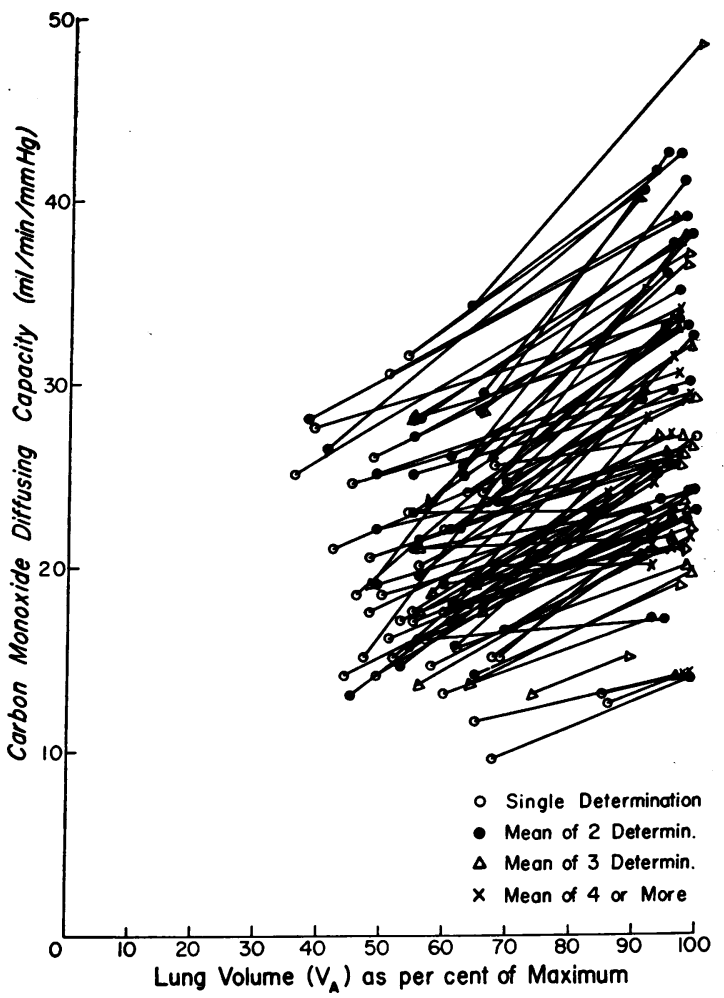

Fig. 7. The Relationship OF SINGLe bReATh DL AND VA IN 98 noRmal subjects. Mean Dl values are shown only for the highest and lowest VA achieved. Individual curves are shown in Figure 2.

Actually, decisive experiments in this regard have yet to be performed. These will have to include steady state DL measurements at various lung volumes without alteration of airway pressure; and single breath measurements without initial Miiller-like maneuver.

Alteration of pulmonary capillary blood volume, $\mathrm{V}_{c}$, may be the decisive factor causing both the changes of single breath DL with VA and the numerical difference from the steady state values The following evidence is cited: all manner of $\mathrm{DL}$ measures have been shown to increase during recumbency (13) and after central venous engorgement (28), both of which cause an increase of $V_{c}$; respiratory gymnastics, such as voluntary hyperventilation, cause an increase of steady state $\mathrm{DL}$ which may equal the increase seen during exercise requiring ventilation of comparable magnitude $(22,26,29)$; positive pressure breathing, which decreases $V_{c}$, tends to decrease the steady state DL even though it causes a considerable increase 
of $\mathrm{VA}$ ( Table V); and negative pressure breathing increases the steady state DL (30). Finally, the instantaneous DL varies with lung volume depending upon the speed and vigor of inspiration (Figure 4). Each of these observations suggests that De changes as the result of variations in $V_{c}$. This inferential evidence has been confirmed recently by direct estimates of $V_{c}(30-32)$.

During normal inspiration the volume of blood returning to the heart increases and, for a few beats, the right ventricular ouput exceeds that of the left. Although this increase is largely due to extracapillary pulmonary and thoracic blood, it must reflect, in part, on $\mathrm{V}_{\mathrm{c}}$. A Müller maneuver has a similar effect. The considerable reduction in intrathoracic pressure incident to maximal inspiration from residual volume for performance of the breath-holding test should have a much more marked effect because, simultaneous with increase in lung volume, the capillary bed is free to expand. Indeed, in one normal subject we were able to show an almost linear relationship between peak negative intrathoracic (esophageal) pressure required for rapid inspiration of various lung volumes and the resulting DL. The instantaneous De is another demonstration of this relationship. Furthermore, Roughton and Forster (17) measured and calculated separately $\mathrm{DL}, \mathrm{DM}_{\mathrm{M}}$ and $\mathrm{V}_{\mathrm{c}}$ during steady state, 30 -second and 10-second breath-holding in five subjects. As always, the 10-second breath-holding DL was much larger ( 50 per cent) than the steady state $D_{L}$, but $D_{M}$ was quite comparable by all three techniques. Interestingly, $\mathrm{V}_{\mathrm{c}}$ averaged $58.9 \mathrm{ml}$ for the steady state method, $66.2 \mathrm{ml}$ for 30 -second breath-holding, and $78.7 \mathrm{ml}$ for 10-second breath-holding. This lends support to our data which suggest that the more violent and the more recent the preceding inspiration, the greater $V_{c}$ and $D L$. As breath-holding proceeds the glottis is closed and the chest is relaxed against $\mathrm{VA}$, or even an expiratory force may be exerted. This Valsalva-like maneuver decreases cardiac output and, presumably, $V_{c}$ and DL. Actually, measured increases of intrathoracic pressure of 37 to $64 \mathrm{~mm} \mathrm{Hg}$ decreased DL by a maximum of 17 per cent (7).

Back pressure. The relative error of each method due to ignoring of back pressure must also be considered. Our procedure and assumptions for estimating effective back pressure, $\mathrm{P}_{\mathrm{e}}$, during the breath-holding test appear to be valid because pressures so obtained corrected for the alinearity of the $1 n \mathrm{FA}_{\mathrm{CO}}$ versus time relationship under a variety of circumstances (Figure 6).

Data for eight normal subjects who had determinations of both single breath DL (at 90 to 100 per cent of VA) and of resting physiological dead space steady state DL are shown in Table VI. The two uncorrected DL values, averaged for several observations, are shown in columns b and h. The mean values for the whole group were 29.9 and $19.2 \mathrm{ml}$ per minute per $\mathrm{mm} \mathrm{Hg}$, respectively. Initial carboxyhemoglobin saturations (column a) were estimated from smoking histories (8). The back pressures effective during the single breath test, $\mathrm{P}_{\mathrm{e}}$ (column $\mathrm{c}$ ), were taken from the curves of Figure 5, and averaged $0.030 \mathrm{~mm} \mathrm{Hg}$. This corrected the single breath $D_{L}$ to a mean value

TABLE VI

The relative effects of back pressure upon single breath and steady state $D L_{c o}$ *

\begin{tabular}{|c|c|c|c|c|c|c|c|c|c|c|c|c|c|c|c|}
\hline \multirow[b]{2}{*}{ Subject } & \multirow[b]{2}{*}{ Sex } & \multirow[b]{2}{*}{$\begin{array}{c}\text { No. } \\
\text { of } \\
\text { cig. }\end{array}$} & \multirow[b]{2}{*}{ Sco } & \multicolumn{5}{|c|}{ Single breath $\mathrm{D}_{\mathbf{L}}$} & \multicolumn{6}{|c|}{ Steady state $D_{L}$} & \multirow[b]{2}{*}{$P_{s}$} \\
\hline & & & & $\begin{array}{l}\text { No. } \\
\text { of } \\
\text { obs. }\end{array}$ & $\mathrm{D}_{\mathbf{L}}$ & $\mathbf{P e}_{\mathbf{e}}$ & $\underset{\text { corr. }}{\mathrm{D}_{\mathbf{L}}}$ & $\begin{array}{c}\text { Changes } \\
\text { of } D_{L} \\
\text { corr. }\end{array}$ & $\begin{array}{l}\text { No. } \\
\text { of } \\
\text { obs. }\end{array}$ & $\overline{\mathrm{V}}_{\mathrm{CO}}$ & $\overline{\mathbf{P}}_{A C O}$ & $\mathrm{D}_{\mathbf{L}}$ & $\underset{\text { corr. }}{\mathrm{DL}_{\mathbf{L}}}$ & $\begin{array}{c}\text { Changes } \\
\text { of } D_{L} \\
\text { corr. }\end{array}$ & \\
\hline & & & (a) & & (b) & (c) & (d) & (e) & & (f) & (g) & (h) & (i) & (j) & $(\mathrm{k})$ \\
\hline $\begin{array}{l}\text { S.W. } \\
\text { M.S. } \\
\text { E.H. } \\
\text { B.F. } \\
\text { A.M. } \\
\text { J.K. } \\
\text { E.G. } \\
\text { A.N. }\end{array}$ & $\begin{array}{l}\mathbf{M} \\
\mathbf{F} \\
\mathbf{M} \\
\mathbf{F} \\
\mathbf{M} \\
\mathbf{M} \\
\mathbf{M} \\
\mathbf{F}\end{array}$ & $\begin{array}{c}0 \\
0 \\
0 \\
<15 \\
30-40 \\
20-30 \\
20-30 \\
0\end{array}$ & $\begin{array}{l}\% \% \\
1.0 \\
1.0 \\
1.0 \\
2.0 \\
6.0 \\
5.0 \\
5.0 \\
1.0\end{array}$ & $\begin{array}{l}5 \\
9 \\
4 \\
3 \\
3 \\
2 \\
3 \\
6\end{array}$ & $\begin{array}{l}36.8 \\
24.7 \\
31.0 \\
22.9 \\
34.2 \\
34.8 \\
33.2 \\
21.2\end{array}$ & $\begin{array}{l}0.018 \\
0.018 \\
0.018 \\
0.025 \\
0.053 \\
0.046 \\
0.046 \\
0.018\end{array}$ & $\begin{array}{l}37.8 \\
24.8 \\
31.5 \\
23.7 \\
37.7 \\
35.7 \\
34.9 \\
21.3\end{array}$ & $\begin{array}{l}\% \\
2.6 \\
0.4 \\
1.6 \\
3.4 \\
9.3 \\
2.4 \\
4.9 \\
0.5\end{array}$ & $\begin{array}{l}2 \\
2 \\
1 \\
2 \\
2 \\
1 \\
1 \\
2\end{array}$ & $\begin{array}{l}2.81 \\
1.85 \\
1.97 \\
2.90 \\
3.93 \\
3.86 \\
2.35 \\
2.44\end{array}$ & $\begin{array}{l}0.133 \\
0.086 \\
0.117 \\
0.154 \\
0.159 \\
0.225 \\
0.144 \\
0.142\end{array}$ & $\begin{array}{l}21.1 \\
21.5 \\
16.8 \\
18.8 \\
24.7 \\
17.2 \\
16.3 \\
17.2\end{array}$ & $\begin{array}{l}24.4 \\
27.2 \\
19.9 \\
22.4 \\
37.1 \\
21.6 \\
24.0 \\
19.7\end{array}$ & $\begin{array}{l}1 \% \\
13.5 \\
20.9 \\
15.5 \\
16.1 \\
33.5 \\
15.8 \\
39.6 \\
13.7\end{array}$ & $\begin{array}{l}0.059 \\
0.011 \\
0.055 \\
0.032 \\
0.055 \\
0.117 \\
0.064 \\
0.028\end{array}$ \\
\hline Mean & & & 2.75 & & 29.9 & 0.030 & 30.9 & 3.1 & & 2.76 & 0.145 & 19.2 & 24.5 & 21.1 & 0.050 \\
\hline
\end{tabular}

* (a) Carboxyhemoglobin saturation estimated from smoking histories (8). (b) Obtained at $\mathrm{V}_{\mathrm{A}}$ between $90-100 \%$ of maximal $\mathrm{V}_{\mathrm{A}}$. (c) Obtained from Figure 5 (CO-Hb dissociation curves applying during breath-holding). (d) $\frac{V_{A}}{B_{A}-47} \ln \left[\frac{P_{A C O}-P_{e}}{P_{A C O}-P_{e}}\right] \times \frac{1}{t}$. (e) $\frac{d-b}{d} \times 100$.

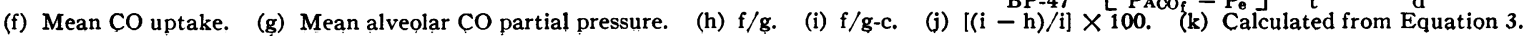


of $30.9 \mathrm{ml}$ per minute per $\mathrm{mm} \mathrm{Hg}$ (column d), an increase of only 3.1 per cent (column e). Application of the same back pressure, $\mathrm{P}_{\mathrm{e}}$, to the steady state DL (column h) increased this value to $24.5 \mathrm{ml}$ per minute per $\mathrm{mm} \mathrm{Hg}$ (column i), a considerably larger change of 21.1 per cent (column $j$ ). The effect of a back pressure correction of given magnitude on the steady state $\mathrm{DL}$ is thus seven times greater than the effect of the same correction on the single breath DL. Nevertheless, the corrected steady state DL (column i) still remains considerably lower than the corrected single breath DL (column d).

If a larger back pressure during the steady state procedure were the only cause for the lower value obtained, then the back pressure during the steady state test, $\mathrm{P}_{\mathbf{s}}$, could be calculated by assuming equality for the two DL values, after correction of the single breath DL for $\mathrm{P}_{\mathrm{e}}$ :

$$
\begin{aligned}
& D_{L} \text { (single breath, corrected for } P_{e} \text { ) } \\
& =\frac{C O \text { uptake (steady state) }}{\text { alveolar CO tension (steady state) }-P_{s}}
\end{aligned}
$$

This equation was solved for $P_{\mathbf{s}}$ for the eight patients shown in Table VI (column $\mathrm{k}$ ). The mean $\mathrm{P}_{\mathrm{s}}$ value for the entire group was $0.050 \mathrm{~mm}$ $\mathrm{Hg}$. Hence, if back pressure were the sole reason for the discrepant values obtained by the two methods, then the back pressure during the steady state test would have to be nearly twice as large as that prevailing during the single breath test. That this hypothetical $\mathrm{P}_{\mathrm{s}}$ pressure is much too high, and that factors other than back pressure must be responsible for the numerical difference between the two tests, is suggested by Linderholm (27). He estimated back pressures obtaining during the steady state DL from arterial blood $\mathrm{CO}$ analyses or from the $\mathrm{CO}$ uptake and an assumed total amount of hemoglobin. In nine subjects studied under the same conditions as ours, that is, at rest breathing 0.1 per cent $\mathrm{CO}$, the mean initial carboxyhemoglobin saturation of 4.7 per cent was nearly twice as great as ours (Table VI), yet back pressures averaged only 0.022 and $0.014 \mathrm{~mm} \mathrm{Hg}$ by the two methods of estimation.

From this we conclude: $a$ ) that the true back pressure for the steady state method must lie between $\mathrm{P}_{\mathrm{e}}$ and $\mathrm{P}_{\mathrm{s}} ; b$ ) that although the actual steady state DL value is probably 20 to 40 per cent larger than the uncorrected value, it still does not equal the single breath DL obtained at maximal $\mathrm{VA}$; and $c$ ) that back pressure alone contributes only in small part to the greater value of the single breath DL.

Finally, it must be questioned whether different techniques sample "the same lung" in a given individual. Forster (19) reviewed the theoretical effects of non-uniformity of lung on estimation of pulmonary diffusing capacity. He concluded that the physiological dead space steady state technique, which is the only steady state method we have used, tends to give lower values for $D_{L}$ than the single breath method, especially in the presence of non-uniform alveolar blood flow:ventilation ratios. Marshall (20) concluded on the basis of results of fractional alveolar gas sampling that steady state methods, particularly the alveolar sampling techniques, measure combined effect of poor diffusion and unequal ventilation while single breath measurements are independent of unevenness of ventilation and affected only by membrane and capillary blood volume. Therefore, he felt that the single breath technique is a measure of the potential diffusing capacity.

Perhaps there is an analogy between $D_{L}$ and lung compliance $\left(C_{L}\right)$ measurements in patients with markedly non-uniform ventilation. In these a very large $C_{L}$ value is obtained during breathholding, because the entire lung is sampled. With increasing frequency of breathing, compliance steadily decreases because there is more and more "trapping," and as a result a progressively smaller and smaller lung is being sampled (33). Indeed, failure of steady state DL to increase with exercise in an occasional patient with severe emphysema may be explained on this basis alone.

If non-uniform ventilation were the sole cause of the numerical difference between steady state and single breath DL measurements, then this difference should be: $a$ ) very small in normal subjects, $b$ ) greater in patients with lung disease, and c) roughly proportional to non-uniformity of lung ventilation as demonstrated by other techniques.

The first of the three suppositions is incorrect. The difference is considerable even in normal subjects (4), suggesting that factors other than nonuniform ventilation must play a role. The second supposition, that the numerical difference should be greater in patients with pulmonary dis- 


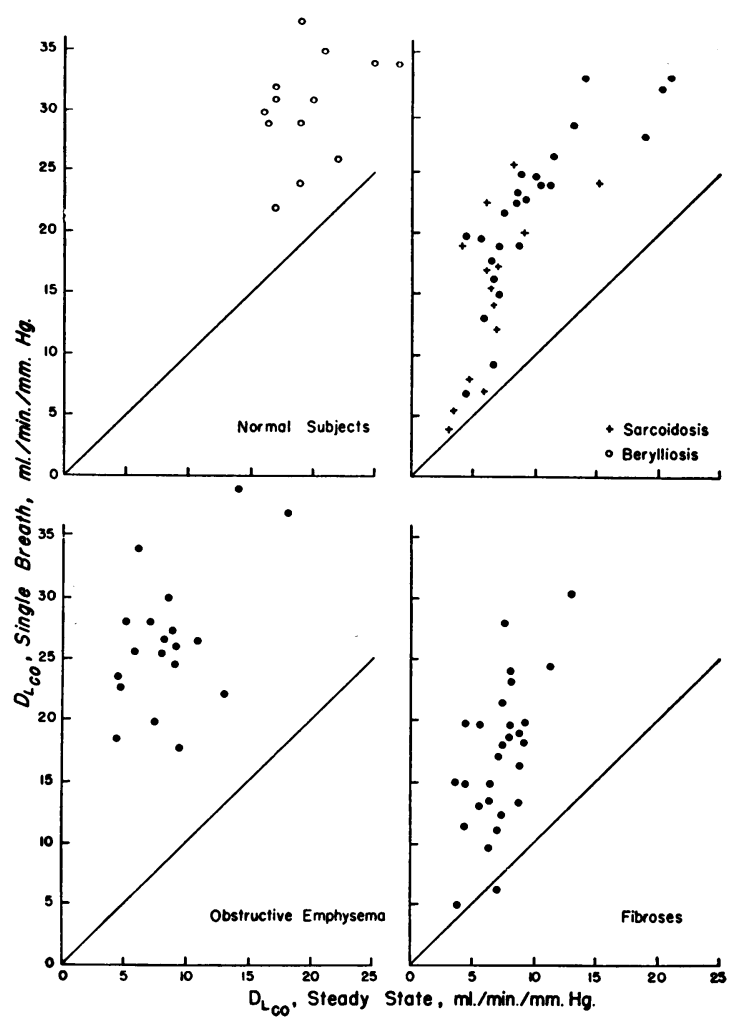

Fig. 8. The Relationship Between the Resting (sitting) Single breath Dl obtained at maximum Va, AND THE RESTING (SUPINE) STEAdY STATE PHYSIOLOGICAL DEAd SPACE Dl iN 13 NORMal SUbJECTS AND IN 85 PATIENTS WITH PULMONARY DISEASE.

ease than in normal subjects, is borne out by a large number of data from our laboratory. Figure 8 shows plots of single breath DL against physiological dead space steady state DL. The single breath value was larger and the discrepancy was greater in patients than in normal subjects, and was greatest in emphysema. In 13 normal young subjects in whom ventilation-perfusion ratios presumably were nearly "ideal," the single breath DL was 1.6 times larger than the steady state DL. In patients with relatively "pure" alveolar-capillary block there is usually unevenness of blood flow $(4,5)$ and occasionally uneven ventilation (34). In 28 such patients with diffuse fibroses, the single breath DL was 2.3 times larger than the steady state De (4). In 14 patients with sarcoidosis and in 24 with berylliosis, including a few with complicating emphysema, it was 2.5 times larger (5). Finally, in 19 patients with moderate to far-advanced emphysema, the single breath DL was 3.4 times or almost 200 per cent larger (35). These relationships are shown in Figure 8.

In emphysema familiar landmarks such as "dead space," "alveolar gas" and "effective ventilation" virtually disappear (33). Therefore, several of the assumptions required for calculation of either $\mathrm{DL}_{\mathrm{O}_{2}}$ or $\mathrm{DL}_{\mathrm{CO}}$ are certainly not true and the required expression of $\overline{\mathrm{P}}_{\mathrm{A}_{\mathrm{CO}}}$ becomes a rather nebulous value. Indeed, Briscoe and co-workers (36) have recently shown that in emphysema the ventilation:perfusion ratio may be ten times higher in well than in poorly ventilated alveoli with corresponding end-capillary oxygen saturations ranging from 97.5 to 76 per cent. They conclude that nonhomogeneity of this severity invalidates $\mathrm{DL}_{\mathrm{L}}$ calculations based upon any single mean $\mathrm{O}_{2}$ or $\mathrm{CO}$ tension, and alveolar ventilation based on equating alveolar $\mathrm{P}_{\mathrm{CO}_{2}}$ with arterial $\mathrm{P}_{\mathrm{CO}_{2}}$. Because of such problems we have never previously reported diffusing capacity measurements in emphysema and, indeed, have always excluded all patients with grossly non-uniform alveolar ventilation from our discussions of diffusion impairment $(4,37)$. However, to test the third supposition, that the discrepancy between steady state and single breath DL measurements should be roughly proportional to non-uniformity of lung ventilation, a comparison was made in the upper half of Figure 9 of 13 normal subjects and of 19 patients with emphysema. The ratios of $\mathrm{DL}$ single breath: DL steady state were plotted against the pulmonary mixing indices or the percentage residual alveolar $\mathrm{N}_{2}$ after 7 minutes' oxygen breathing (9), a moderately sensitive test of the non-uniformity of alveolar ventilation. A close relationship was readily demonstrated. In normal subjects and in patients with less than 2 per cent residual $\mathrm{N}_{2}$, the single breath $\mathrm{DL}$ was at most 2 times larger than the steady state value; with residual $\mathrm{N}_{2}$ from 2 to 6 per cent it was up to 3.5 times larger; and with severely uneven ventilation, usually in bullous emphysema, it was as much as 5 times larger. The data further show that patients with severest emphysema had the lowest steady state diffusing capacity; and that the lower this steady state DL, the greater the discrepancy between it and the single breath value, as demonstrated in the lower plot of Figure 9.

These observations suggest that inequalities of ventilation, of perfusion or of ventilation-perfusion 
ratios, are important factors in the discrepancy between results of physiological dead space steady state and single breath DL methods. At least in some individuals the two tests do not sample "the same lung."

\section{SUMMARY AND CONCLUSIONS}

The helium dilution modification of the Krogh single breath technique is an attractive method for measurement of the apparent diffusing capacity of the lungs (DL) because it is bloodless and, with known residual volume, requires but a few minutes. However, experience with this method during the past 7 years has emphasized certain problems. These were: $a$ ) failure of repeated tests to check closely, $b$ ) a much larger numerical result than that obtained with $\mathrm{O}_{2}$ or $\mathrm{CO}$ steady state De techniques in normal subjects, and $c$ ) an even greater discrepancy in patients

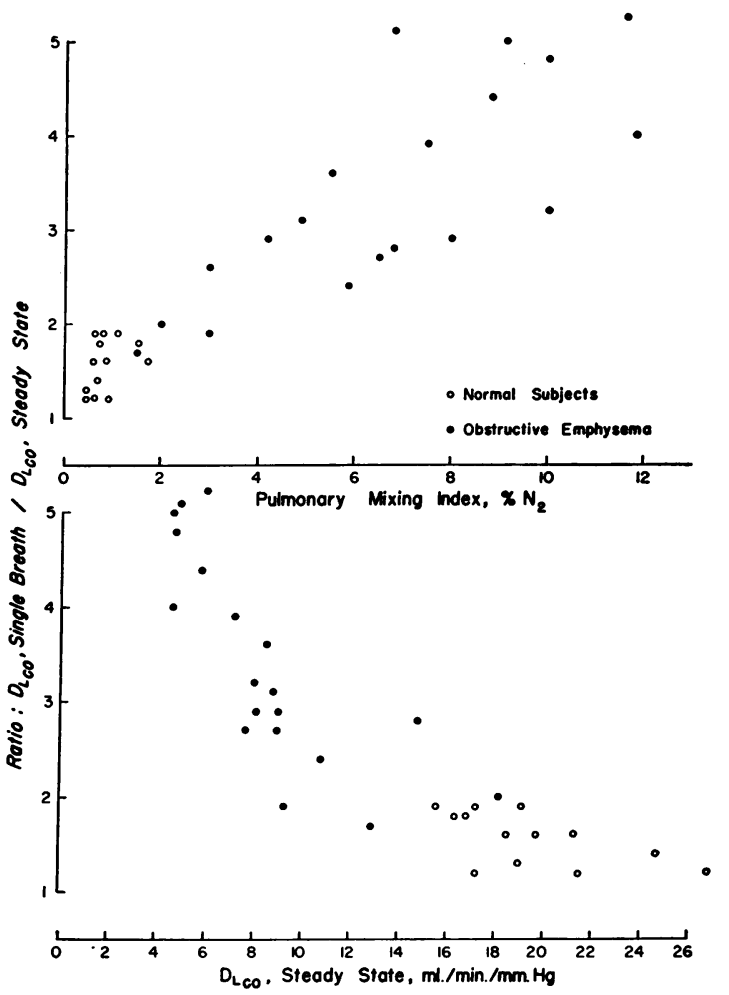

Fig. 9. The ratio of Resting Single breath DL: STEADY STATE DL COMPARED WITH (TOP) THE ALVEOLAR NITROGEN CONCENTRATION AFTER 7 MINUTES' OXYGEN BREATHING (THE PULMONARY MIXING INDEX) AND (BOTTOM) WITH THE ACTUAL STEADY STATE DL, IN 13 NORMAL SUBJECTS AND IN 19 PATIENTS WITH MODERATELY TO FARADVANCED CHRONIC OBSTRUCTIVE EMPHYSEMA. with pulmonary disease. The following observations were made in an attempt to clarify these problems.

Variations between multiple tests were found to be due to variations in the volume of the lungs (VA) at which the breath was held. In normal subjects the coefficient of variation was reduced from 8.9 to 3.2 per cent merely by holding VA constant; and in patients who took a "deepest possible breath" duplicate tests had a coefficient of variation of 10.7 per cent which was reduced to 2.6 per cent if VA was controlled at 95 to 100 per cent of total lung capacity.

A quantitative relationship between $\mathrm{DL}_{\mathrm{L}}$ and $\mathrm{VA}_{\mathrm{A}}$ was demonstrated. Four to $15 \mathrm{DL}$ determinations were made at various lung volumes: in 14 normal subjects a 92 per cent increase of VA caused an average increase of DL of 47 per cent and of more than 70 per cent in 3 subjects; in 15 patients this increase averaged 60 per cent. Changes of similar magnitude were observed during exercise. Subsequently, with over 600 determinations in 98 normal subjects this DL-VA relationship failed to occur only four times.

Both in normal subjects and in patients, the single breath De was invariably larger than the "physiological dead space" steady state DL.

The following variables were considered to explain these observations :

1. The effective CO "back pressure" did not measurably alter duplicate single breath determinations. However, in five normal subjects a 1 per cent increase of carboxyhemoglobin ( $\mathrm{COHb}$ ) saturation decreased the apparent DL by 0.15 to $0.32 \mathrm{ml}$ per minute per $\mathrm{mm} \mathrm{Hg}$, and at 25 per cent $\mathrm{COHb}$ saturation the $\mathrm{DL}$ was, on the average, $6.8 \mathrm{ml}$ per minute per $\mathrm{mm} \mathrm{Hg}$ less than at zero $\mathrm{COHb}$ saturation. Effective back pressure was from 1.3 to 2.5 times greater than estimates obtained from Haldane's relationship. Although back pressure caused an underestimation of the average single breath DL of only 3.1 per cent and of the average steady state DL by 21.1 per cent, this did not fully explain the discrepant results. Back pressure did explain the previously observed alinearity in the relationship of the duration of breath-holding to the natural logarithm of alveolar CO concentration.

2. An increase of the diffusing capacity of the 
lung membrane ( $D M)$ due to breath-holding at full inspiration was considered possible, particularly since the steady state DL nearly always fell at functional residual capacity (FRC) on the curve relating single breath DL and VA. However, experimental increase of FRC in a body plethysmograph failed to increase the steady state DL.

3. Variations of the pulmonary capillary blood volume $\left(V_{\mathrm{c}}\right)$ were thought to be largely responsible for both the larger value of the single breath test and for variations with VA. Experiments with "instantaneous DL" determinations suggested that the single breath $\mathrm{DL}$ value is a complex of a rapidly rising DL during the Müller-like maneuver of forced deep inspiration, and a decreasing DL during the subsequent Valsalva-like breath-holding. Measured peak negative intrathoracic pressure during forced inspiration appeared related to $V_{c}$ and hence to DL. Maneuvers tending to increase $V_{c}$ (Müller maneuver, "G-suit" inflation, recumbency, brief breath-holding, hyperventilation) tend to increase $\mathrm{DL}$ while maneuvers tending to decrease $\mathrm{V}_{c}$ (Valsalva, positive pressure breathing, long breath-holding) decrease DL.

4. Inequalities of ventilation, of perfusion or of ventilation:perfusion ratios were called upon to explain the increasingly greater discrepancy between steady state and single breath $\mathrm{DL}$ in patients with pulmonary disease. In 13 normal subjects the single breath value was, on the average, 1.6 times greater than the physiological dead space steady state DL; it was 2.3 times greater in 28 patients with a variety of pulmonary fibroses, many of whom had marked lung shunt without complicating emphysema $; 2.5$ times greater in 38 patients with various sarcoidal reactions some of whom had slight emphysema; and 3.4 times greater in 19 patients with moderate to severe obstructive emphysema. In the last group there was a close relationship between single breath $D_{L}$ : steady state DL ratio and the lung nitrogen after 7 minutes' oxygen breathing. It appeared that the two tests did not sample "the same lung."

From the clinical standpoint our experiences suggest that for multiple serial or follow-up studies, the single breath test is useful only when related to the VA at which the breath was held. Further, an abnormally low single breath De implies serious impairment of the apparent diffusing capacity of the lungs while a normal value, particularly in patients with very uneven lungs, does not rule out serious "effective" impairment of the lungs to diffuse $\mathrm{O}_{2}$ or CO. As a corollary, steady state $\mathrm{DL}_{\mathrm{CO}}$ or $\mathrm{DL}_{\mathrm{O}_{2}}$ values cannot be estimated from single breath $\mathrm{DL}_{\mathrm{CO}}$.

\section{APPENDIX}

In the derivation of the instantaneous $\mathrm{D}_{\mathrm{L}}$ given below, comparison is made between algebraic expressions and the graphic presentation of Figure 4:

Let $\mathrm{R}=\mathrm{dV}_{\mathrm{A}} / \mathrm{dt}$, the rate of inspiration, a constant;

$\mathrm{V}_{\mathrm{A}}=$ alveolar volume at any time, $\mathrm{t}$, of inspiration;

$\mathrm{VCO}_{\mathrm{i}}=$ volume of $\mathrm{CO}$ which has entered the lungs;

$\mathrm{Fa}_{\mathrm{i}}=$ fraction of $\mathrm{CO}$ which would have obtained from inspired $\mathrm{CO}$ alone if diffusion out of the lungs had not occurred;

$\mathrm{VCO}_{\mathrm{p}}=$ volume of $\mathrm{CO}$ actually present at time $\mathrm{t}$;

$\mathrm{VCO}_{\mathrm{D}}=$ volume of $\mathrm{CO}$ which has diffused out of lungs;

$\mathrm{F}_{\mathrm{A}}=$ actual observed fraction of $\mathrm{CO}$ (curve $\mathrm{B}$ );

$\mathrm{F}_{\mathrm{I}}=$ fraction of $\mathrm{CO}$ in inspired gas. If dead space and $\mathrm{CO}$ back pressure are ignored then

$$
\mathrm{VcO}_{\mathrm{i}}=\mathrm{F}_{\mathrm{I}} \mathrm{R}_{\mathrm{t}}
$$

so that by definition

Also

$$
\begin{gathered}
\mathrm{Fa}_{\mathrm{i}}=\frac{\mathrm{Vco}_{\mathrm{i}}}{\mathrm{V}_{\mathrm{A}}} ; \text { and } \mathrm{Fa}_{\mathrm{i}}=\frac{\mathrm{F}_{\mathrm{I}} \mathrm{R}_{\mathrm{t}}}{\mathrm{V}_{\mathrm{A}}} \text { (curves } \mathrm{A} \text { ) } \\
\mathrm{Vco}_{\mathrm{p}}=\mathrm{V}_{\mathrm{A}} \mathrm{F}_{\mathrm{A}}
\end{gathered}
$$

Then the volume diffused out is the difference between that which has entered and that which is present:

$$
\mathrm{VCO}_{\mathbf{i}}-\mathrm{VCO}_{\mathbf{p}}=\mathrm{VCO}_{\mathrm{D}}
$$

Substituting Equations 1 and 3 into Equation 4:

$$
\mathrm{VCO}_{D}=\mathrm{F}_{\mathrm{I}} \mathrm{R}_{\mathrm{t}}-\mathrm{V}_{\mathrm{A}} \mathrm{F}_{\mathrm{A}} \quad \text { (curve } \mathrm{C} \text { ) }
$$

Differentiating Equation 5 with respect to $t$ :

$$
\begin{array}{r}
\frac{d V_{C O}}{d t}=F_{I} R-F_{A}\left[\frac{d V_{A}}{d t}\right]-V_{A}\left[\frac{d F_{A}}{d t}\right] \\
\text { (slope of curve C) }
\end{array}
$$

and since $d V_{A} / d t=R$

$$
\frac{d V c O_{D}}{d t}=R\left(F_{I}-F_{A}\right)-V_{A}\left[\frac{d F a_{i}}{d t}\right]
$$

But by definition our instantaneous $D_{L}$ is :

$$
\begin{gathered}
D_{L}=\left[\frac{d V c O_{D}}{d t}\right] \times \frac{1}{713 \times F_{A}} \\
D L_{\text {inst }}=\frac{R\left(F_{I}-F_{A}\right)-V_{A}\left[\frac{d F_{A}}{d t}\right]}{713 \times F_{A}} \\
\text { (equation for curve D) }
\end{gathered}
$$


Note that in Equation 9, values for $R, F_{I}, F_{A}$ and $V_{A}$ are known for any given instant from experimental data; $\mathrm{dF}_{\mathrm{A}} / \mathrm{dt}$ is not, however, and a graphic method for calculation of DL must still be relied upon.

\section{ACKNOWLEDGMENT}

The authors gratefully acknowledge the continued constructive criticism, advice and many helpful suggestions of Dr. Robert E. Forster during the past six years.

\section{REFERENCES}

1. Bohr, C. Über die spezifische Tätigkeit der Lungen bei der respiratorischen Gasaufnahme und ihr Verhalten zu der durch die Alveolarwand stattfindenden Gasdiffusion. Skand. Arch. Physiol. 1909, 22, 221.

2. Krogh, M. The diffusion of gases through the lungs of man. J. Physiol. (Lond.) 1914, 49, 271.

3. Forster, R. E., Fowler, W. S., Bates, D. V., and Van Lingen, B. The absorption of carbon monoxide by the lungs during breathholding. J. clin Invest. 1954, 33, 1135.

4. Marks, A., Cugell, D. W., Cadigan, J. B., and Gaensler, E. A. Clinical determination of the diffusion capacity of the lungs. Comparison of methods in normal subjects and patients with alveolarcapillary block syndrome. Amer. J. Med. 1957, $22,51$.

5. Gaensler, E. A., Verstraeten, J. M., Weil, W. B., Cugell, D. W., Marks, A., Cadigan, J. B., Jr., Jones, R. H., and Ellicott, M. F. Respiratory pathophysiology in chronic beryllium disease. $\mathrm{Re}$ view of thirty cases with some observations after long-term steroid therapy. A. M. A. Arch. industr. H1th 1959, 19, 132.

6. Forster, R. E., II, Briscoe, W. A., and Bates, D. V. Pulmonary diffusing capacity at different lung volumes. Fed. Proc. 1954, 13, 46.

7. Ogilvie, C. M., Forster, R. E., Blakemore, W. S., and Morton, J. W. A standardized breath holding technique for the clinical measurement of the diffusing capacity of the lung for carbon monoxide. J. clin. Invest. 1957, 36, 1.

8. Gaensler, E. A., Cadigan, J. B., Jr., Ellicott, M. F., Jones, R. H., and Marks, A. A new method for rapid precise determination of carbon monoxide in blood. J. Lab. clin. Med. 1957, 49, 945.

9. Darling, R. C., Cournand, A., and Richards, D. W., Jr. Studies on the intrapulmonary mixture of gases. III. An open circuit method for measuring residual air. J. clin. Invest. 1940, 19, 609.

10. Gaensler, E. A., and Cugell, D. W. Bronchospirometry. V. Differential residual volume determination. J. Lab. clin. Med. 1952, 40, 558.

11. Jones, R. H., Ellicott, M. F., Cadigan, J. B., and Gaensler, E. A. The relationship between alveolar and blood carbon monoxide concentrations during breathholding. Simple estimation of $\mathrm{COHb}$ saturation. J. Lab. clin. Med. 1958, 51, 553.
12. Filley, G. F., MacIntosh, D. J., and Wright, G. W. Carbon monoxide uptake and pulmonary diffusing capacity in normal subjects at rest and during exercise. J. clin. Invest. 1954, 33, 530.

13. Bates, D. V., and Pearce, J. F. The pulmonary diffusing capacity; a comparison of methods of measurement and a study of the effect of body position. J. Physiol. (Lond.) 1956, 132, 232.

14. Shephard, R. J. "Breath-holding" measurement of carbon monoxide diffusing capacity. Comparison of a field test with steady-state and other methods of measurement. J. Physiol. (Lond.) 1958, 141, 408.

15. Roughton, F. J. W. The average time spent by the blood in the human lung capillary and its relation to the rates of $\mathrm{CO}$ uptake and elimination in man. Amer. J. Physiol. 1945, 143, 621.

16. Forster, R. E., Fowler, W. S., and Bates, D. V. Considerations on the uptake of carbon monoxide by the lungs. J. clin. Invest. 1954, 33, 1128.

17. Roughton, F. J. W., and Forster, R. E. Relative importance of diffusion and chemical reaction rates in determining rate of exchange of gases in the human lung, with special reference to true diffusing capacity of pulmonary membrane and volume of blood in the lung capillaries. J. appl. Physiol. 1957, 11, 290.

18. Grape, B., and Tyler, J. M. The effect of altering lung volume on pulmonary diffusion of carbon monoxide. Clin. Res. Proc. 1958, 6, 313.

19. Forster, R. E. Exchange of gases between alveolar air and pulmonary capillary blood: Pulmonary diffusing capacity. Physiol. Rev. 1957, 37, 391.

20. Marshall, R. A comparison of methods of measuring the diffusing capacity of the lungs for carbon monoxide. Investigation by fractional analysis of the alveolar air. J. clin. Invest. 1958, 37, 394.

21. Mittman, C., and Burrows, B. Uniformity of pulmonary diffusion: Effect of lung volume. J. appl. Physiol. 1959, 14, 496.

22. Ross, J. C., Frayser, R., and Hickam, J. B. A study of the mechanism by which exercise increases the pulmonary diffusing capacity for carbon monoxide. J. clin. Invest. 1959, 38, 916.

23. Donevan, R. E., Palmer, W. H., Varvis, C. J., and Bates, D. V. Influence of age on pulmonary diffusing capacity. J. appl. Physiol. 1959, 14, 483.

24. Kruhøffer, P. Studies on the lung diffusion coefficient for carbon monoxide in normal human subjects by means of $\mathrm{C}^{14} \mathrm{O}$. Acta physiol. scand. 1954, 32, 106.

25. Barcroft, J. Features in the Architecture of Physiological Function. Cambridge; Cambridge University Press, 1938.

26. Turino, G. M., Brandfonbrener, M., and Fishman, A. P. The effect of changes in ventilation and pulmonary blood flow on the diffusing capacity of the lung. J. clin. Invest. 1959, 38, 1186. 
27. Linderholm, $\mathrm{H}$. On the significance of $\mathrm{CO}$ tension in pulmonary capillary blood for determination of pulmonary diffusing capacity with the steady state CO method. Acta med. scand. 1957, 156, 413.

28. Ross, J. C., Lord, T. H., and Ley, G. D. Effect of pressure-suit inflation on pulmonary-diffusing capacity. J. appl. Physiol. 1960, 15, 843.

29. Macnamara, J., Prime, F. J., and Sinclair, J. D. An assessment of the steady-state carbon monoxide method of estimating pulmonary diffusing capacity. Thorax 1959, 14, 166.

30. Cotes, J. E., Snidal, D. P., and Shepard, R. H. Effect of negative intraalveolar pressure on pulmonary diffusing capacity. J. appl. Physiol. 1960, $15,372$.

31. Rosenberg, E., and Forster, R. E. Changes in diffusing capacity of isolated cat lungs with blood pressure and flow. J. appl. Physiol. 1960, 15, 883.

32. Johnson, R. L., Jr., Spicer, W. S., Bishop, J. M., and Forster, R. E. Pulmonary capillary blood volume, flow and diffusing capacity during exercise. J. appl. Physiol. 1960, 15, 893.

33. Mead, J., Lindgren, I., and Gaensler, E. A. The mechanical properties of the lungs in emphysema. J. clin. Invest. 1955, 34, 1005.

34. Read, J., and Williams, R. S. Pulmonary ventilation: Blood flow relationships in interstitial disease of the lungs. Amer. J. Med. 1959, 27, 545.

35. Grenda, A. N., and Gaensler, E. A. Unpublished data.

36. Briscoe, W. A., Cree, E. M., Filler, J., Houssay, H. E. J., and Cournand, A. Lung volume, alveolar ventilation and perfusion interrelationships in chronic pulmonary emphysema. J. appl. Physiol. 1960, 15, 785.

37. Cugell, D. W., Marks, A., Ellicott, M. F., Badger, T. L., and Gaensler, E. A. Carbon monoxide diffusing capacity during steady exercise. Comparison of physiologic and histologic findings in patients with pulmonary fibroses and granulomatoses. Amer. Rev. Tuberc. 1956, 74, 317. 